\title{
Role of MHC-Linked Susceptibility Genes in the Pathogenesis of Human and Murine Lupus
}

\author{
Manfred Relle and Andreas Schwarting \\ First Department of Medicine, University Medical Center of Johannes Gutenberg University of Mainz, 55131 Mainz, Germany \\ Correspondence should be addressed to Manfred Relle, relle@uni-mainz.de
}

Received 24 February 2012; Accepted 7 May 2012

Academic Editor: Harris Perlman

Copyright ( $) 2012$ M. Relle and A. Schwarting. This is an open access article distributed under the Creative Commons Attribution License, which permits unrestricted use, distribution, and reproduction in any medium, provided the original work is properly cited.

\begin{abstract}
Systemic lupus erythematosus (SLE) is a chronic autoimmune disease characterized by the production of autoantibodies against nuclear antigens and a systemic inflammation that can damage a broad spectrum of organs. SLE patients suffer from a wide variety of symptoms, which can affect virtually almost any tissue. As lupus is difficult to diagnose, the worldwide prevalence of SLE can only be roughly estimated to range from 10 and 200 cases per 100,000 individuals with dramatic differences depending on gender, ethnicity, and location. Although the treatment of this disease has been significantly ameliorated by new therapies, improved conventional drug therapy options, and a trained expert eye, the underlying pathogenesis of lupus still remain widely unknown. The complex etiology reflects the complex genetic background of the disease, which is also not well understood yet. However, in the past few years advances in lupus genetics have been made, notably with the publication of genome-wide association studies (GWAS) in humans and the identification of susceptibility genes and loci in mice. This paper reviews the role of MHC-linked susceptibility genes in the pathogenesis of systemic lupus erythematosus.
\end{abstract}

\section{Introduction}

Chronic autoimmune diseases have complex pathogeneses and the course of events leading to these diseases is not well understood. They arise from a dysfunction of the immune system, recognizing self-antigens as foreign, which can lead to inflammation and severe damage of tissues and organs. One of these complex inflammatory diseases is called systemic lupus erythematosus (SLE). The etiology of lupus is multifactorial with environmental, hormonal, ethnic, and genetic factors [1].

In the 70s and 80s of the last century mouse models of spontaneous lupus, like $(\mathrm{NZB} \times \mathrm{NZW})$ F1 hybrids, BXSB mice (which carry the disease-accelerating Yaa gene on the $\mathrm{Y}$ chromosome [2-4]), MRL/lpr mice (MRL mice homozygous for a fas mutation $[5,6]$ ) or MRL/gld mice (MRL mice homozygous for a fasL mutation $[7,8]$ ) were established [912]. Research based upon these mice revealed that a number of genes, loci, and pathways are directly associated with lupus in both mouse and human species (reviewed in [13-17]). In addition, by means of these models signaling pathways were identified that are dysregulated in both human and murine lupus. Hence, mouse models will continue to serve as invaluable instruments for studying the genetic basis of lupus susceptibility, because they depict the genetic facets of the human systemic lupus erythematosus (SLE).

Recent findings suggest that aberrant epigenetic mechanisms may be involved in the pathogenesis of lupus [18], and a number of genes have been claimed to be targets of these alterations [19]. However, the mechanisms underlying epigenetic changes are poorly understood. Deciphering the contribution of epigenetic alterations to the pathogenesis of lupus will provide promising insights in this complex autoimmune disease and epigenetic pharmaceuticals will offer new therapeutic options to treat SLE.

One of the genetic risk factors for the development of lupus (or other immune-mediated diseases) are genes linked to the major histocompatibility complex (MHC) [20]. In humans, HLA antigens have long been associated with SLE and, therefore, these susceptibility genes are extensively studied [21]. Certain HLA class II genes or haplotypes 
seem to be particularly involved on lupus pathogenesis [14, 22-24]. HLA class III genes, such as those encoding the complement components C2 and C4, may also be considered as risk factors for the development of a lupus-like disease in different ethnicities [25]. In mice, it could also be shown that the MHC class II locus directly participates in lupus disease susceptibility similar to that observed in humans [26]. The effect of MHC-linked complement factors on disease expression is strongly dependent on the background genes, reflecting the genetic unification of inbred mice in comparison to wildtype mice.

However, the role of certain MHC haplotypes, genes, or alleles in lupus pathogenesis is still controversially discussed. For this reason and to update the most recent scientific research on this topic, this paper reviews the role of $\mathrm{MHC}$ genes and alleles in the pathogenesis of both human and murine lupus.

\section{The Major Histocompatibility Complex (MHC)}

2.1. Historical Overview. More than a century ago, it was observed that tissue transplants (now called allografts) of one animal were rejected when transferred to a different laboratory mouse. At the Jackson Laboratory Gorer showed in 1937 that so-called H or "histocompatibility antigens" on the surface of mouse cells account for this [27, 28]. Seven years later, it was Medawar who showed that allograft rejection is a host versus graft reaction $[29,30]$. At the same time, Snell developed congenic mice strains that were genetically identical except at the H-2 locus. With the aid of these mice he could show that the H-2 antigens were "controlled" by genes at the H-2 complex on chromosome 17 and called this multigene locus "major histocompatibility complex" (MHC) [31-33]. In 1958, the first human alloantigen present on leucocytes was detected by Dausset, which was later called HLA-A2 [34, 35]. A few years later Payne and coworkers depicted the first human multiallelic system, now known as the HLA class I loci HLA-A and HLA-B [36]. However, it was clear from the beginning that allograft rejection or acceptance is not the physiological function of MHC molecules. In the early sixties, experiments of Benacerraf et al. with guinea pigs and synthetic amino acid polymers showed that there is a single genetic locus which controls the immune system's ability to respond to foreign antigens and called the (autosomal dominant) genes of this locus "immune response genes" (or Ir genes) [37-39]. In the late 1960's, McDevitt found that the Ir genes were linked to the MHC [40, 41]. The concept of immune response genes was refined by Zinkernagel and Doherty (in 1974), who made the breakthrough discovery that the ability of virus-specific T lymphocytes to combat a virus infection is dependent upon the simultaneous recognition of both "foreign" molecules of the virus and self molecules (i.e., major histocompatibility proteins) [42]. This limitation or narrowing of antigen recognition by $\mathrm{T}$ cells was called "MHC-restricted antigen recognition" or in short, "MHC restriction" and was subsequently confirmed in many other systems. One year before Zinkernagel and Doherty made their pioneering discovery, the first disease-associated
MHC allele, namely, HLA-B27, was reported. HLA-B27 is strongly associated with ankylosing spondylitis $[43,44]$.

2.2. Genetics of HLA and $H$-2. The major histocompatibility complex is located on the short arm of chromosome 6 in humans and on the telocentric chromosome 17 in mice $[45,46]$. The genes coding for the classical transplantation antigens as well as the so-called "class III" polypeptides are located within this multigene region [47-49]. About $40 \%$ of the expressed MHC genes encode proteins related to immune defense [48]. Whereas the classical class I and class II transplantation antigens are expressed on cells and tissues (with the exception of proteins involved in antigen processing and presentation of antigens to the immune system, such as LMPs, TAPs, and Tapasin), the class III antigens are secreted proteins which do not play a role in tissue acceptance or graft rejection. Class III antigens comprise proteins with immune functions such as components of the complement cascade (C2, C4, and factor B), cytokines (TNF- $\alpha$, LTA, LTB), steroid metabolism (Cyp21B), heat shock proteins (hsp70), and many other genes not directly associated with immune responses [50]. For historical reasons, human MHC polypeptides are called "human leukocyte antigens" (HLA) and mouse MHC proteins "histocompatibility 2" (H-2) antigens.

In humans, the $\mathrm{MHC}$ is the most gene-dense region of the genome, and the MHC genes themselves are the most polymorphic genes known so far. Among the $\sim 3$ billion base pairs of the human or murine genome, arranged on 23 and 20 chromosomes, respectively, there are 20,000-30,000 protein-coding genes [51-53]. That means that an average of one gene was found for every 100,000 to 150,000 base pairs. The human MHC, however, contains more than 120 functional genes and additional nonfunctional pseudogenes in both mice and humans distributed over 3.6 Mbp [54-57]. The outcome of this is an average of approximately one gene for every 30,000 base pairs.

MHC molecules are codominant expressed and clustered in so-called "haplotypes". The term was introduced by Ceppellini et al. (in 1967), who used familial genotype data, to explain the coinheritance of alleles at two closely linked loci [58]. This organization is thought to facilitate recombination events that generate new alleles and therefore, contribute to the high polymorphism of $\mathrm{MHC}$ proteins. Polymorphism derives from the creek word " $\pi \mathrm{o} \lambda \nu \mu \mathrm{o} \rho \varphi \dot{\alpha} \alpha$ " (polymorphia) and means "many or complex shapes". The polymorphism found in the MHC class II genes is generally limited to exon 2, which encodes the peptide-binding groove [59]. Due to the high frequency of MHC alleles, most individuals will be heterozygous for each different MHC gene locus. Each MHC molecule in the population has a different spectrum of peptide binding. This insures that no one pathogen can destroy the whole population by developing protein sequences that are incapable of binding to an MHC molecule, and thus evading the immune system (Figure 3 ).

In contrast to humans the number of $\mathrm{MHC}(\mathrm{H}-2)$ alleles is strongly reduced in inbred mice because of the homozygosity at their MHC loci. As many peptides are not recognized by the remaining alleles/haplotypes, these mice often 
have an impaired immune response against pathogens. In fact, the MHC genes of mice were first called "immune response (Ir) genes because of strain-dependent defects in responses to certain antigens [38].

2.3. Evolution of MHC Diversity. In the sixties and seventies, two different models have been developed to explain the high heterogeneity of the MHC genes: Negative frequency dependence (rare allele advantage) and heterozygote advantage (overdominance model) [60-62]. The negative frequency dependence postulates that rare MHC alleles (of recent origin) may have a selective advantage, as no pathogen may be adapted to it [63]. The overdominance model states that polymorphism will be advantageous because heterozygous individuals are able to recognize a wider range of pathogens and parasites [60]. A main difference between these two types of (balancing) selection is that overdominance is based upon a stable polymorphism, whereas a polymorphism maintained by frequency dependence will be dynamic [64]. However, there is still a controversy, if the heterozygote advantage on its own is sufficient to explain the high degree of MHC polymorphism [65]. For instance, it has recently been shown that balancing selection can also result from MHCdependent choice of mates [66].

Evolution of MHC genes and alleles is driven by the need to maximize peptide binding diversity in order to recognize a maximum of potential pathogens. Polymorphism and polygeny are two (independent) genetic mechanisms for increasing variety of MHC class I and class II proteins. Polygeny acts on the individual level, whereas polymorphism is (primarily) a population-relevant criterion. Thus, a maximum number of class I and II genes would ensure the greatest conceivable protection of a single individual against pathogens. However, polygeny is limited by a mechanism called "MHC restriction": T cells recognize fragmented antigens (self and foreign) only in conjunction with MHC proteins $[42,67]$. To avoid autoimmune reactions, $\mathrm{T}$ cells that strongly react with MHC molecules presenting selfpeptides are deleted. In consequence of these opposed requirements, the immune surveillance is a delicate balance between self and foreign as well as between (self-)tolerance and immune response. Furthermore, these two opposing demands create a dilemma: On the one hand, many MHC genes would present a maximum of different peptides but on the other hand, the presentation of many different self-antigens would strongly reduce the $\mathrm{T}$ cell diversity. Thus, MHC restriction limits $\mathrm{T}$ cell antigen recognition and response. As a consequence of this, the diversity of MHC class I and II proteins of a single individual is limited (and optimized) to six different molecules ( 3 genes $\times 2$ alleles). The optimal number is called "immunogenetic optimum" [68]. Due to the limited number of MHC genes, some agents may evolve polypeptides that evade the immune system of single individuals, but the enormous polymorphism within a population diminishes the possibility that a pathogen can exterminate a whole species (individual C). However, there is a major drawback of this kind of defense strategy: if the size of a population decreases strongly, some MHC haplotypes will disappear, leading to a reduction of MHC diversity, which in turn will negatively affect survival of the population [69]. In summary, the number of different MHC genes is a delicate balance between the key requirement of an entire population/species and the core requests of its individuals.

\section{How Is Lupus Erythematosus Influenced by the MHC?}

Variations within the MHC locus seem to be associated with a great variety of autoimmune diseases. Consequently, the contribution of HLA genes to lupus pathology has recently been extensively studied [21, 70-72]. However, due to the extensive linkage disequilibrium among alleles throughout this locus, the causal relationship between these MHC variations and autoimmune pathogenesis have remained elusive for the great majority of these diseases, including lupus [73].

Although the pathogenesis of the disease is still poorly understood and a number of environmental factors have been postulated, genetic predisposition is clearly a major risk parameter for SLE $[74,75]$. There is strong evidence for a genetic component based upon a high concordance rate of SLE in monozygotic twins as well as the occurrence of SLE in $5-12 \%$ of the relatives of affected patients [76-79]. The complex nature of SLE reflects a polygenic inheritance of the disease rather than a monogenic mode. Several genes are known to contribute to SLE susceptibility $[80,81]$, because they affect key pathways, implicating immune complexes, host immune signal transduction, and interferon pathways (reviewed in [82]). Only in a small proportion of patients $(<5 \%)$, a single gene seems to be responsible for the disease onset. Many of these genes relate to the early complement components from which the $\mathrm{C} 2$ and $\mathrm{C} 4$ genes are linked to the MHC (Figure 1 and [83-85]).

The mechanisms underlying antigen recognition are of great importance to human autoimmune diseases. A number of genes have been claimed to be associated with susceptibility to anti-self responses. Because of their considerable heterogeneity, the immunoglobulin genes, the $\mathrm{T}$ cell receptor genes, and the major histocompatibility complex (MHC) genes have soon been suspected of playing a distinct role in the pathology of lupus and other autoimmune diseases. Particularly, the MHC class II allotypes HLA-DR2 and -DR3 seem to be related to (and/or positively correlated with) lupus disease [86-88]. Genes, like angiotensin-converting enzyme (ACE) or angiotensinogen (AGT), that specifically increase kidney susceptibility to lupus pathogenesis have also been described [89].

Advances in high throughput technology have enabled the genotyping of hundreds of thousands of single nucleotide polymorphisms (SNPs) in a single individual and genomewide association studies (GWAS) in lupus patients [90]. GWAS in European- or East Asian-ancestry populations [9194] and high-density screenings [20, 95] have identified several independent SNPs in the MHC region associated with SLE. Some of these SNPs could be confirmed in a recent targeted association study [96]. GWAS may also been used to decipher complex ethnic disparities in SLE prevalence rates. For unknown reasons, the prevalence of lupus in African and Hispanic Americans is two to fivefold higher compared to 


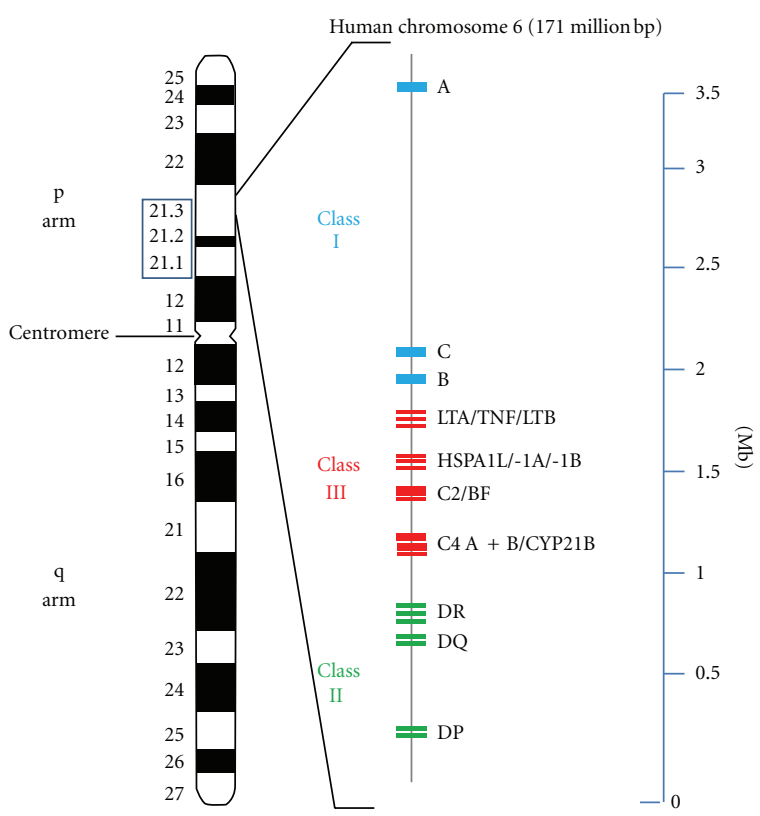

Figure 1: HLA gene cluster and lupus susceptibility genes on human chromosome 6. Ideogram of chromosome 6 (left) and schematic diagram of the MHC-complex-associated genes ranging from $6 \mathrm{p} 21.1$ to $6 \mathrm{p} 21.3$ (middle). The class I gene complex contains three major loci (A, C, and B), as well as additional (unmentioned) loci. The resulting class I polypeptides associate with the invariable beta- 2 microglobulin, encoded by a gene on chromosome 15 . The HLA-B locus is known as the most polymorphic gene within the human genome. Class II MHC molecules are composed of two glycosylated polypeptide subunits (called $\alpha$ and $\beta$ chain) of approximately equal length. Whereas HLA-DP and -DQ code for one alpha- and one beta-chain polypeptide, respectively, the genetics of HLA-DR is more complex: It consists of one locus coding for the alpha subunit and 4 loci coding for beta subunits. Unlike the other DR loci, DRA is not polymorphic. Even though the $\mathrm{DR} \beta$-chain is encoded by 4 loci, no more than two are present on a single chromosome. DRB1 is the most polymorphic gene of the class II locus. Class I and class II antigens are membrane proteins whereas almost all class III polypeptides are serum proteins (including the complement components $\mathrm{C} 2, \mathrm{C} 4 \mathrm{~A}, \mathrm{C} 4 \mathrm{~B}$, and factor B) or can be detected in other body fluids. Therefore, the term "class III" is misleading, as this locus does not contain a distinct class of genes. The coding regions of the genes are shown as small blue (class I), green (class II), and red (class II) rectangles, respectively. Abbreviations: LTA: lymphotoxin A, LTB: lymphotoxin B, TNF: tumor necrosis factor alpha, HSPA1L: heat shock $70 \mathrm{kDa}$ protein 1like, HSPA1A: heat shock $70 \mathrm{kDa}$ protein 1A, HSPA1B: heat shock $70 \mathrm{kDa}$ protein $1 \mathrm{~B}, \mathrm{BF}$ : complement factor $\mathrm{B}, \mathrm{CYP} 21 \mathrm{~B}$ : cytochrome P450 21-hydroxylase and Mb: mega base pairs.

Americans of European ancestry [97]. A recent SNP screening of the MHC region revealed for independent SNP signals for African American women [98]. The strongest signal of this study (the SNP rs9271366), was also associated with SLE in a previous Chinese GWA study of Han and coworkers [91]. It has also been shown by GWAS that several established non-MHC lupus loci are not related to other autoimmune diseases, which suggests a limited genetic overlap between these diseases and SLE [99]. In summary, it can be stated that genome-wide and -targeted association studies, despite of their methodological and application-related limitations, are useful tools to localize lupus-associated genes.

In the past few years, progress has been made in identifying lupus susceptibility genes in mice [100, 101]. Meanwhile, a large number of lupus susceptibility loci have been detected in mouse models, and some of the corresponding susceptibility genes have been identified by now (reviewed in [10, 102-106]) including those linked to $\mathrm{MHC}[14,107,108]$. An important milestone in murine lupus genetics was the identification of the SLE loci 1-3 by Mohan et al. and Morel et al. in NZM2410 mice [109-111], a lupus-prone strain derived from a cross between NZB and NZW mice [112]. The identification of these loci provided the starting basis for a rapidly growing number of publications that dissected the role of single loci or genes in lupus development [113-119]. Several B6-based lupus congenic strains has been characterized, that carry the NZM2410-derived SLE-susceptibility loci Sle1, Sle2, and Sle3 (reviewed in [17]). It has been shown that these three loci act in an additive way and that the coexpression of them is necessary to develop the full severity of the disease $[107,120]$. Subsequently, it has been demonstrated by congenic dissection and polygenic analyses that both protective suppressor and harmful susceptibility loci form the genetic basis for murine lupus and that they act in a highly complex manner that involves several genes [121, 122]. Meanwhile, for a subset of these murine genes, involvement in human SLE has been established [17].

Based upon these models, there is considerable evidence that single MHC genes contribute to the development of systemic lupus erythematosus [26, 123-125]. However, in both mice and humans, lupus susceptibility results from accumulating effects of a large number of individual gene variants [126] of which the MHC-linked loci are reviewed below.

3.1. MHC Class I Genes. The association between MHC loci and susceptibility to lupus has been known since 1971, when HLA-B8 was shown to be associated with this disease [21]. In particular, the ancestral haplotype A1-B8-DR3 has been linked to lupus susceptibility [127-130]. Nevertheless, early studies have focused upon MHC class II genes in lupus pathogenesis, since class II-restricted $\mathrm{CD} 4^{+} \mathrm{T}$ cells have been associated with the generation of autoantibodies [131]. Although the dysregulation of class I levels is predicted to result in autoimmunity [132], the relevance of MHC class I proteins to lupus, however, is less clear. Recent studies have implicated a distinct role for MHC (H-2) class I molecules in mouse lupus pathogenesis: $\mathrm{McPhee}$ et al. could demonstrate that $\beta 2$-microglobulin-deficient $(\beta 2 \mathrm{~m})$ BXSB-Yaa and -SJL mice (i.e., mice deficient in class I antigen presentation) developed much more aggressive and lethal forms of a lupuslike disease that characterizes these strains [133]. These results are in line with previous findings in the $(\mathrm{NZB} \times$ NZW) F1 mouse model of lupus disease [125]. A more sophisticated role for class I proteins could be demonstrated for $\beta 2 \mathrm{~m}$-deficient MRL/lpr mice: While inhibiting nephritis, $\beta 2 \mathrm{~m}$ deficiency accelerates spontaneous lupus skin disease [134]. In another report, Mozes et al. could show that MHC class I-deficient mice are resistant to experimental SLE, 
although these mice were not generally poor responders to antigen [135]. Furthermore, MHC class I-deficient MRL/lpr mice demonstrate a substantial reduction in CD4/CD8 double-negative (DN) T cells and symptoms of the lupus-like disease [136]. In summary, these results indicate that class Idependent $\mathrm{T}$ cells are key players for the murine lupus-like syndrome.

3.2. MHC Class II Genes. SLE is associated with class II genes of the MHC, but it is not yet clear which haplotypes, genes, or alleles are primarily responsible for disease association. Initial reports looking at the involvement of HLA in SLE assumed a direct involvement of haplotypes containing DR2 and/or DR3 to disease pathogenesis [22, 137-140], but later reports indicated for both humans and mouse models that HLA DR molecules may have an increased association with the production and specificity of autoantibodies rather than with the disease itself [75, 141-143]. Meanwhile, an immense number of studies based on different ethnicities have identified HLA class II associations with SLE.

The presence of antinuclear antibodies (ANA) is a serological hallmark of lupus erythematosus (found in the serum of most patients) [144], and the role of HLA genes in autoantibody expression has been intensely researched, because it indicates the activation of autoaggressive B cells and the breakdown of tolerance to self-antigens. A subspecies of antinuclear autoantibodies, called Ro/SSA (a ribonuclear protein) is present in $25-50 \%$ of SLE cases $[145,146]$ and the level and occurrence of theses autoantibodies correlate with the presence of HLA-DR2/DR3 and HLA-DQw1/DQw2 heterozygotes [147]. In mouse models, heterozygosity at the MHC (H-2) locus has also been associated with lupus susceptibility and enhanced autoantibody production [148, 149]. For $(\mathrm{NZB} \times \mathrm{NZW})$ F1 hybrid mice, it has been hypothesized that $\mathrm{H}-2 \mathrm{~A}$ or $\mathrm{H}-2 \mathrm{E}$ MHC class II genes are two likely candidates [81]. DQA ${ }^{*} 0102$ and $\mathrm{DQA} 1 * 0301$ alleles were observed to be strongly associated with the presence anti-Ro/La and anti-dsDNA antibodies in Chinese but not in a Malaysian control group [150]. However, a German lupus study showed that all HLA-DR and -DQ (homozygous and heterozygous) combinations appear with frequencies expected from the observed gene frequencies, suggesting that gene complementation at MHC class II loci seems not to contribute to lupus susceptibility [151].

Other autoantibodies are detected in patients with SLE but the HLA associations with these are less clear. Antiphospholipid antibodies are frequently observed in patients with SLE [152-154] and a significant association of DR7-positive patients (in linkage disequilibrium with the HLA-DR gene B4) that carry anticardiolipin antibodies could be observed by Savi et al. [155]. Azizah et al. found a significant association of the DQB1*0601 allele with anti-Sm/RNP, DR2 with anti-Ro/La, and DR2, DRB1*0501, and DRB1*0601 with anti-dsDNA antibody expression [156].

It has been shown that the HLA haplotype DR3-DQ2C4AQ0 is strongly associated with SLE in Caucasians [157, 158]. A strong association with lupus was also determined by DNA typing for DQA1* 0501 in Scandinavian patients [159]. However, this allele was in linkage disequilibrium with DR3 and DR5. A strong association to SLE is found with DRB1*03 and DOB $1^{*} 0201$ alleles of central European patients [160]. A genetic predisposition of HLA DR2- and/or HLA DR3containing haplotypes for SLE has also been described for German, Kuwaiti, and Chinese lupus patients [161-163].

Strong associations of class II genes with lupus susceptibility have also been shown by GWA studies. Studies based on sequence length polymorphisms in European populations identified a potential association of the class II HLA-DRB1 alleles HLA-DRB1*08:01, - * 03:01, and - * 15:01 with SLE [73, 164]. Two of these alleles (HLA-DRB1 ${ }^{*} 03: 01$ and $-* 15: 01$ ) have also been identified in a recent study of the IMAGEN consortium using high-density SNP typing across the MHC [20]. In a study of Ruiz-Narvaez et al. the strongest SLEassociated SNP was the rs9271366 near the HLA-DRB1 gene [98]. This SNP was also associated with higher risk of SLE in a previous GWAS [91]. Although there are hardly any GWAS results concerning class III genes, the SNP rs419788 in intron 6 of the class III gene SKIV2L was found to be independently associated with SLE [165]. However, in a recent report this SNP was not found to be independent from the rs3135391 (HLA-DRB1*15:01) signal [96].

In summary, these results indicate that both DR2 and DR3 and their associated DQ alleles seem to play a role in SLE $[146,166]$. However, most of the results concerning the contribution of individual MHC class II polymorphisms to SLE have been obtained from population-based case-control studies and need to be confirmed in family-based studies [146].

MRL/lpr mice spontaneously develop aggressive autoimmune kidney disease characterized by an immune complex glomerulonephritis, which is associated with increased (or de novo) renal expression of major histocompatibility complex (MHC) class II molecules and a massive systemic expansion of CD4-CD-double negative (DN) T cells [167-169]. However, these mice are homozygous for the $\mathrm{H}-2^{k}$ haplotype, which is shared by several other strains, that do not develop lupus-like symptoms. In addition, it has been shown that genes encoded within or closely linked to the MHC region regulate autoantigen selection and isotype switching to IgG3 but have minimal effect on end-organ damage or survival in $\mathrm{MRL} / \mathrm{lpr}$ mice [170]. On the other hand, MHC (H-2) class II expression appears to be required for the development of autoaggressive $\mathrm{CD}^{+}{ }^{+} \mathrm{T}$ cells involved in autoimmune nephritis, because MHC class II-deficient MRL/lpr mice do neither produce serum anti-DNA antibodies nor develop proliferative renal disease in contrast to their wild-type counterparts [168].

In contrast to New Zealand black (NZB) and New Zealand white (NZW) mice, F1 hybrids of these strains (with a H-2 ${ }^{d / z}$ haplotype) spontaneously develop a severe lupuslike immune complex glomerulonephritis associated with the production of antinuclear autoantibodies [171]. Morel et al. have focused on the genetic dissection of lupus-prone NZM2410 mice, which are derived from this cross [110, 112] and identified four epistatic modifiers (Sles1-4) by linkage analysis. The cumulative effect of these suppressive loci accounts for the benign autoimmunity in NZW mice [122]. 


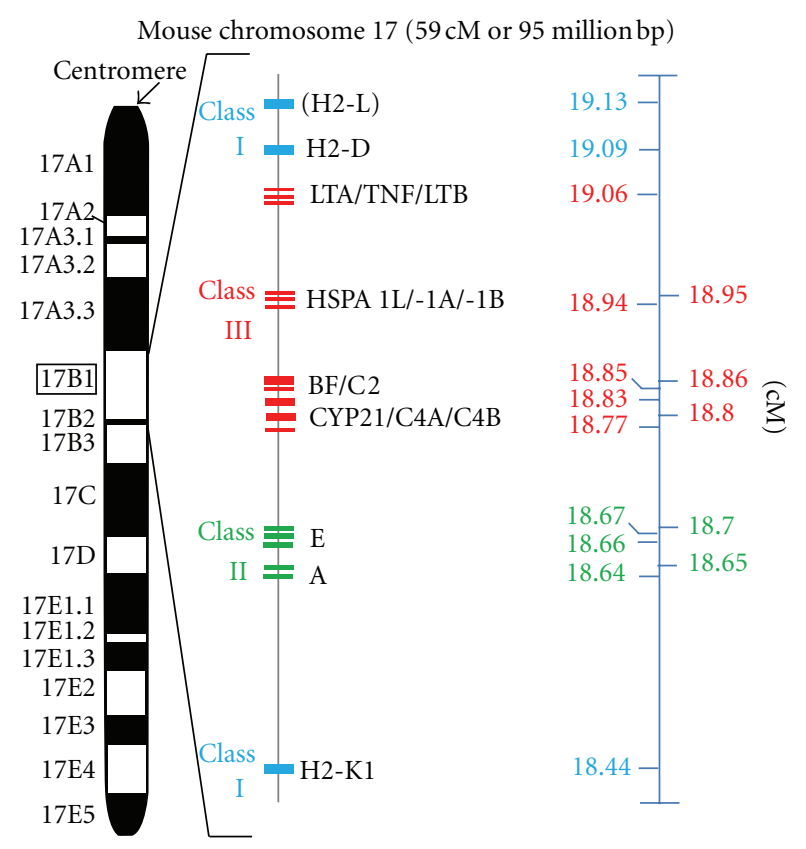

Figure 2: H-2 gene cluster and lupus susceptibility genes on mouse chromosome 17. Ideogram of chromosome 17 (middle) and schematic diagram of the MHC-complex-associated genes at $17 \mathrm{~B} 1$ (boxed left). The coding region of the genes is shown as small blue (class I), green (class II), and red (class II) rectangles, respectively. There are 11 mouse $\mathrm{MHC}$ subclasses, ranging from 18.4 to 20.3 centimorgan (cM). However, the organization of the "classical" MHC classes is similar in human and mouse. The MHC class I consists of two major loci, $\mathrm{K}$ and $\mathrm{D}$, which are (unlike the human MHC class I counterpart) separated by the class II and class III genes. The class II gene complex is known as the I region (from "immune response") and the class II genes are also termed "Ir genes". Class III lupus susceptibility genes are tumor necrosis factor alpha (TNF), cytochrome P450 21-hydroxylase a1 (CYP21) as well as the complement factors C2, C4A, and C4B, respectively. Note, that $\mathrm{cM}$ is a nonlinear genetic distance unit of recombinant frequency, which is influenced by several factors. Further abbreviations: LTA: lymphotoxin A, LTB: lymphotoxin B, HSPA1L: heat shock $70 \mathrm{kDa}$ protein 1-like, HSPA1A: heat shock $70 \mathrm{kDa}$ protein $1 \mathrm{~A}$, HSPA1B: heat shock $70 \mathrm{kDa}$ protein $1 \mathrm{~B}$, and $\mathrm{BF}$ : complement factor B. Source of mapping data: IMGT information system (http://www.imgt.org/IMGTrepertoireMHC/LocusGenes/): Artzt et al. (1991), Mammalian Genome 1: 280ff. [232], and Endo et al. [233], Gene 205: 19ff. [233].

The strongest one, Sles 1 , being encoded by an $\mathrm{MHC}\left(\mathrm{H}-2^{z}\right)$ class II locus, was sufficient to completely prevent autoimmunity initiated by Sle1 in $(\mathrm{NZW} \times$ B6.NZMc1)F1 mice.

MHC $\mathrm{H}-2^{d / z}$ heterozygosity $\left(\mathrm{H}-2^{d}\right.$ of NZB and $\mathrm{H}-2^{z}$ of NZW mice) promotes lupus disease, as congenic $\mathrm{H}-2^{d / d}$ and $\mathrm{H}-2^{z / z}$ homozygous crosses do not develop severe disease $[172,173]$. On the other hand, Zhang and coworkers found that $\mathrm{H}-2 \mathrm{~A}^{d / d}$ homozygous $(\mathrm{NZB} \times \mathrm{NZW}) \mathrm{F} 1$ mice lacking $\mathrm{H}-2 \mathrm{E}$ molecules developed severe SLE similar to that seen in wild-type $\mathrm{F} 1$ mice, whereby the effect of $\mathrm{H}-2 \mathrm{E}$ is greatly influenced by the haplotype of H-2A molecules [174]. The authors propose two different mechanisms to explain their results: First, compared with $\mathrm{H}-2^{d / d} \mathrm{~F} 1$ mice, the self-antigen presenting capacity of DCs in $\mathrm{H}-2^{d / z} \mathrm{~F} 1$ is much higher, so that effects of $\mathrm{E}$ molecules may be insufficient for disease suppression and, alternatively, generation of $\mathrm{H}-2^{d / z} \mathrm{~F} 1$ unique self-reactive $\mathrm{T}$ cells restricted to haplotype mismatched $\mathrm{H}-2 \mathrm{~A} \alpha / \beta$ heterodimers in the thymus may play a role in an H-2E molecule-independent manner. However, one should keep in mind that $\mathrm{H}-2^{d / z}$ heterozygosity is a necessary but not sufficient condition for the development of autoimmunity in NZB/W F1 mice [175]. Kotzin and coworkers wanted to dissect the role of $E a^{z}, E b^{z}, A a^{z}$, and $A b^{z}$ MHC class II molecules to lupus susceptibility, but they could not observe an increased contribution of these polypeptides to the seriousness of the disease in transgenic approaches $[26,123]$.

BXSB mice spontaneously develop a male-biased lupuslike syndrome that is accelerated by the Yaa (Y-linked autoimmune accelerator) gene $[9,176]$. The BXSB MHC locus (H-2b haplotype) plays a crucial role in disease expression since congenic BSXB.H-2d mice have a less severe syndrome [2]. As B6-Yaa (H-2b/b) mice do not develop lupus symptoms, there are also non-MHC-linked genes in the BSXB genome that contribute to disease development [104]. It has been shown that lupus was initiated by a translocation of 17 genes, including TLR7, from the $\mathrm{X}$ to the $\mathrm{Y}$ chromosome [3, 4]. TLR7 overexpressing transgenic mice have demonstrated that duplication of the TLR7 gene is the sole requirement for this accelerated autoimmunity, as reduction of TLR7 gene dosage abolishes the Yaa phenotype [177]. Furthermore, TLR7 and additional nucleic acid-binding TLRs, consisting of the toll-like receptors 3 and 9, exacerbate lupus-like disease in other autoimmune-prone strains [178]. Although a TLR7 gene copy-number variation could be detected in the human genome, it was not significantly increased among SLE patients as compared with the healthy control group, and no significant concordance between the number of gene copies and the SLE phenotype was found [179]. However, other reports describe SNPs in the human TLR7 gene that associate with lupus $[180,181]$. García-Ortiz and coworkers reported an association between increased TLR7 gene copy numbers and childhood-onset SLE in the Mexican children [182].

However, even after more than 30 years of research, the precise contribution of HLA class II genes to lupus pathogenesis remains ambiguous and is still a matter of discussion.

3.3. MHC Class III Genes. Class III genes of the MHC encode proteins that are not involved in antigen presentation (Figures 1 and 2). C2, C4A, C4B, and factor B are complement components that constitute both the $\mathrm{C} 3$ convertases of the classical and alternative pathway $[183,184]$. Tumor necrosis factor alpha (TNF- $\alpha$ ) and its related proteins lymphotoxin- $\alpha$ and $-\beta$ are immune modulating cytokines of the TNF superfamily $[185,186]$, and the heat shock protein 70 (Hsp70) orthologues are a triplet of genes, which are important components of the chaperone machinery $[187,188]$.

3.3.1. Complement Components. The complement system plays an important role in innate and adaptive immunity [189]. Its main biological function is to recognize foreign particles, macromolecules, and apoptotic cells, and to 


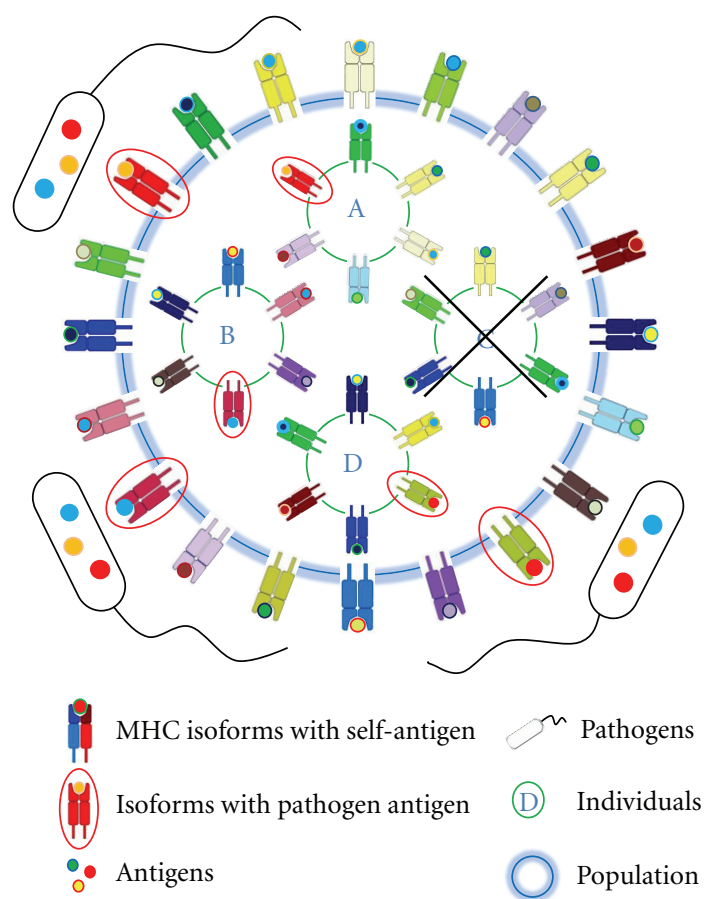

FIGURE 3: Protective effect of MHC polymorphism on populations (simplified scheme). Evolution of MHC genes and alleles is driven by the need to maximize peptide binding diversity in order to recognize a maximum of potential pathogens. Thus, the extreme polymorphism of MHC molecules of vertebrates is thought to reflect a pathogen-driven selection. This insures that no germ can exterminate the whole population by developing peptides that cannot be bound by any MHC molecule. However, compared to the enormous diversity of MHC molecules within a population (outer circle), their heterogeneity within a single individual is restricted to a few different MHC polypeptides (individuals A-D). This can be attributed to a mechanism called "MHC restriction" (see MHC chapter) that limits polygeny of the MHC genes (in general to 3 genes per MHC class I and class II). As a consequence some agents may evolve polypeptides that evade the immune system of single individuals (individual C) and harm or even kill them. In consequence of these opposed requirements, the immune surveillance is a delicate balance between (self-)tolerance and immune response that ensures survival of a population and/or a species at the expense of single individuals.

support their elimination either by opsonisation or lysis [190]. Although rare, inappropriate complement activation as well as complement deficiencies are involved in the pathophysiology of systemic lupus erythematosus [25, 191, 192].

Lupus is casually associated with the homozygous deficiency of the most early components of the complement activation pathway (C1q, C1r, C1s) [189, 193]. However, MHClinked $\mathrm{C} 2$ and C4 deficiencies are also associated with SLE [194], and approximately 40\% of C2 deficient individuals develop SLE-like symptoms [195]. In fact, homozygous C2 deficiency is thought to be the most common inherited complement defect associated with lupus [196, 197]. In addition, Fielder et al. found a high frequency of null alleles at the C2, C4A, and C4B loci in families of SLE patients [198]. In humans and mice, C4 is encoded by two tandemly arranged genes (C4A and B) within the MHC ([199] and Figures 1 and 2 ). About 40 protein variants for $\mathrm{C} 4$ have been documented [200]. It has been shown that low copy numbers of the C4 gene are a risk factor for SLE in European Americans [201] and a large C4A-CYP21A gene deletion (particularly associated with HLA-B44, -DR2, and -DR3 alleles) in black Americans [202]. On the other hand, C3 deficiency is only rarely associated with lupus development, because homozygous hereditary C3 deficiency is a seldom genetic disease [203]. It is thought that absence of complement proteins results in a defective immune complex clearance and, in consequence, to a deposition of the complexes in various organs [204, 205]. An alternative hypothesis postulates that self-reactive B cells, which are specific for lupus autoantigens, are not effectively silenced (or eliminated) without complement [206]. In fact, recent findings suggest, that enhanced $B$ cell function is the defining pathogenic event of lupus pathogenesis, leading to autoimmunity and organ damage [207].

Aberrant splicing of the C4 mRNA (caused by an intronic insertion of the $\mathrm{B} 2$ sequence in the $\mathrm{C} 4$ gene) is the basis for low $\mathrm{C} 4$ expression in $\mathrm{H}-2^{k}$ mice, such as lupus-prone MRL mice $[208,209]$. An association between complement deficiency and SLE has also been shown for complementdeficient mouse models [210]. C1q- and C4-deficient mice develop a lupus-like disease and exhibit impaired clearance of apoptotic cells [211]. Indeed, apoptotic cells are thought to be a major source of the autoantigens of SLE [212]. This has led to the hypothesis that the delayed clearance of apoptotic material leads to a persistence of proinflammatory activities which may then initiate autoimmunity.

3.3.2. Heat Shock Protein (HSP) Genes. Heat shock proteins (hsp) are highly conserved proteins that regulate protein folding. They are induced by a variety of stresses like heat, growth factors, inflammation, and infection [213]. The expression of hsp90 is found to be increased in the mononuclear cells of about one-fourth of SLE patients and antibodies to this protein are detected in patients with SLE [146]. Levels of hsp90 protein in SLE patients seem to correlate with IL-6 and hsp90 autoantibody levels, supporting the following scenario: Elevated levels of IL6 in SLE patients induce higher levels of hsp90 protein which in turn results in the production of hsp90 autoantibodies [214].

Another heat shock protein that play a role in SLE pathogenesis is HSPA1B, a member of the hsp70 gene family. The HSPA1A, HSPA1B, and HSPA1L are MHC class III genes in murines and humans, which code for highly homologous polypeptides [215]. HSPA1B encodes a polypeptide that is thought to be involved in disease susceptibility [216]. Association of a polymorphism (A to G transition) in the coding region of the HSPA1B gene with SLE in African Americans has been reported in a case-control study [217].

3.3.3. Tumour Necrosis Factor (TNF) Gene. Tumour necrosis factor alpha (TNF- $\alpha)$ is an inducible member of the TNF/ TNFR superfamily with a broad range of immunological effects [218]. Macrophages are the major source of TNF$\alpha$, although it can be produced by many other cell types 
as well [219]. It is generally known as a proinflammatory cytokine, stimulating the acute phase response and increasing MHC class I and II expression as well as antigendriven lymphocyte proliferation [220-222]. Dysregulation of TNF- $\alpha$ production has been implicated in a variety of human diseases, including lupus. A rare polymorphism (G to A transition) in the promoter region has been found to be increased in patients with SLE in a case-control study $[223,224]$, which is probably due to linkage disequilibrium with DR3 [225]. However, other reports based on Caucasian SLE patients describe an independent contribution of TNF polymorphisms and HLA-DR3 to SLE susceptibility [226, 227].

As in humans, the murine TNF- $\alpha$ gene is located within the MHC [228]. The NZW mouse strain carries a unique TNF allele, that expresses only limited amounts of TNF- $\alpha$ [229]. It has been proposed that this polymorphism ameliorates murine lupus symptoms $[228,230]$ and, indeed, it has been shown by Kontoyiannis and Kollias, that autoimmunity and lupus nephritis is accelerated in NZB mice with an engineered heterozygous deficiency in tumor necrosis factor [231].

\section{Concluding Remark}

The MHC genes including TNF $\alpha$, HSP70, and class II genes have been associated with systemic lupus erythematosus. However, in most cases, genetic susceptibility to lupus is not caused by a single gene or allelic variation. Defects in complement genes are well-documented exceptions, which may predispose to lupus because of the persistence of antibody complexes or activation of self-reactive B cells. The role of TNF $\alpha$, HSP70, or MHC class II gene loci in lupus pathology is more difficult to evaluate. This is due, among others, to the linkage disequilibrium of the MHC, which makes it difficult to prove a direct contribution of single genes or alleles to lupus susceptibility. Furthermore, the identification of susceptibility or suppressor genes is complicated by the plain fact that SLE is a highly heterogeneous disease that appears when susceptibility and suppressor loci are unbalanced. In addition, environmental, epigenetic, hormonal, and infectious factors may alter the epigenetic status quo and may trigger lupus in geneticallysusceptible individuals. On the other hand, analysing the influence of environmental factors on the epigenetic status of well-defined MHC haplotypes or MHC gene polymorphisms may open promising perspectives for future studies.

For these reasons, deciphering the contribution of MHC locus and its gene products to the pathogenesis of human and murine lupus will add the next important piece of the puzzle that will further clarify the etiology of this complex autoimmune disease.

\section{Acknowledgment}

This work was supported by Center of Excellence (SFB548, "Analysis and modulation of allergies and autoimmune diseases") of the Deutsche Forschungsgemeinschaft (DFG).

\section{References}

[1] A. Rahman and D. A. Isenberg, "Systemic lupus erythematosus," The New England Journal of Medicine, vol. 358, no. 9, pp. 929-939, 2008.

[2] R. Merino, L. Fossati, M. Lacour, R. Lemoine, M. Higaki, and S. Izui, "H-2-1inked control of the Yaa gene-induced acceleration of lupus-like autoimmune disease in BXSB mice," European Journal of Immunology, vol. 22, no. 2, pp. 295-299, 1992.

[3] S. Subramanian, K. Tus, Q. Z. Li et al., "A Tlr7 translocation accelerates systemic autoimmunity in murine lupus," Proceedings of the National Academy of Sciences of the United States of America, vol. 103, no. 26, pp. 9970-9975, 2006.

[4] P. Pisitkun, J. A. Deane, M. J. Difilippantonio, T. Tarasenko, A. B. Satterthwaite, and S. Bolland, "Autoreactive B cell responses to RNA-related antigens due to TLR7 gene duplication," Science, vol. 312, no. 5780, pp. 1669-1672, 2006.

[5] J. L. Chu, J. Drappa, A. Parnassa, and K. B. Elkon, "The defect in Fas mRNA expression in MRL/lpr mice is associated with insertion of the retrotransposon, ETn," The Journal of Experimental Medicine, vol. 178, no. 2, pp. 723-730, 1993.

[6] R. Watanabe-Fukunaga, C. I. Brannan, N. G. Copeland, N. A. Jenkins, and S. Nagata, "Lymphoproliferation disorder in mice explained by defects in Fas antigen that mediates apoptosis," Nature, vol. 356, no. 6367, pp. 314-317, 1992.

[7] D. H. Lynch, M. L. Watson, M. R. Alderson et al., "The mouse fas-ligand gene is mutated in gld mice and is part of a TNF family gene cluster," Immunity, vol. 1, no. 2, pp. 131-136, 1994.

[8] T. Takahashi, M. Tanaka, C. I. Brannan et al., "Generalized lymphoproliferative disease in mice, caused by a point mutation in the Fas ligand," Cell, vol. 76, no. 6, pp. 969-976, 1994.

[9] B. Andrews, R. A. Eisenberg, and A. N. Theofilopoulos, "Spontaneous murine lupus-like syndromes. Clinical and immunopathological manifestations in several strains," The Journal of Experimental Medicine, vol. 148, no. 5, pp. 11981215, 1978.

[10] A. N. Theofilopoulos and F. J. Dixon, "Murine models of systemic lupus erythematosus," Advances in Immunology, vol. 37, pp. 269-390, 1985.

[11] P. L. Cohen and R. A. Eisenberg, "Lpr and gld: single gene models of systemic autoimmunity and lymphoproliferative disease," Annual Review of Immunology, vol. 9, pp. 243-269, 1991.

[12] S. Izui, M. Iwamoto, L. Fossati, R. Merino, S. Takahashi, and N. Ibnou-Zekri, "The Yaa gene model of systemic lupus erythematosus," Immunological Reviews, no. 144, pp. 137156, 1995.

[13] C. Nguyen, N. Limaye, and E. K. Wakeland, "Susceptibility genes in the pathogenesis of murine lupus," Arthritis Research, vol. 4, supplement 3, pp. S255-S263, 2002.

[14] T. J. Vyse and B. L. Kotzin, "Genetic basis of systemic lupus erythematosus," Current Opinion in Immunology, vol. 8, no. 6, pp. 843-851, 1996.

[15] M. L. Santiago-Raber, C. Laporte, L. Reininger, and S. Izui, "Genetic basis of murine lupus," Autoimmunity Reviews, vol. 3, no. 1, pp. 33-39, 2004.

[16] L. Li and C. Mohan, "Genetic basis of murine lupus nephritis," Seminars in Nephrology, vol. 27, no. 1, pp. 12-21, 2007.

[17] L. Morel, "Genetics of SLE: evidence from mouse models," Nature Reviews Rheumatology, vol. 6, no. 6, pp. 348-357, 2010. 
[18] E. Ballestar, M. Esteller, and B. C. Richardson, "The epigenetic face of systemic lupus erythematosus," Journal of Immunology, vol. 176, no. 12, pp. 7143-7147, 2006.

[19] B. M. Javierre and B. Richardson, "A new epigenetic challenge: systemic lupus erythematosus," Advances in Experimental Medicine and Biology, vol. 711, pp. 117-136, 2011.

[20] J. D. Rioux, P. Goyette, T. J. Vyse et al., "Mapping of multiple susceptibility variants within the $\mathrm{MHC}$ region for 7 immunemediated diseases," Proceedings of the National Academy of Sciences of the United States of America, vol. 106, no. 44, pp. 18680-18685, 2009.

[21] F. C. Grumet, A. Coukell, J. G. Bodmer, W. F. Bodmer, and H. O. McDevitt, "Histocompatibility (HL-A) antigens associated with systemic lupus erythematosus. A possible genetic predisposition to disease," The New England Journal of Medicine, vol. 285, no. 4, pp. 193-196, 1971.

[22] J. B. Harley, K. L. Moser, P. M. Gaffney, and T. W. Behrens, "The genetics of human systemic lupus erythematosus," Current Opinion in Immunology, vol. 10, no. 6, pp. 690-696, 1998.

[23] L. A. Criswell, "The genetic contribution to systemic lupus erythematosus," Bulletin of the NYU Hospital for Joint Diseases, vol. 66, no. 3, pp. 176-183, 2008.

[24] F. K. Tan and F. C. Arnett, "The genetics of lupus," Current Opinion in Rheumatology, vol. 10, no. 5, pp. 399-408, 1998.

[25] M. J. Walport, "Complement and systemic lupus erythematosus," Arthritis Research, vol. 4, supplement 3, pp. S279S293, 2002.

[26] S. J. Rozzo, T. J. Vyse, C. S. David, E. Palmer, S. Izui, and B. L. Kotzin, "Analysis of MHC class II genes in the susceptibility to lupus in New Zealand mice," Journal of Immunology, vol. 162, no. 5, pp. 2623-2630, 1999.

[27] P. A. Gorer, "The genetic and antigenic basis of tumour transplantation," Journal of Pathology and Bacteriology, vol. 44, pp. 691-697, 1937.

[28] P. B. Medawar, "Peter Alfred Gorer. 1907-1961," Biographical Memoirs of Fellows of the Royal Society, vol. 7, pp. 95-109, 1961.

[29] P. B. Medawar, "The behaviour and fate of skin autografts and skin homografts in rabbits: a report to the War Wounds Committee of the Medical Research Council," Journal of Anatomy, vol. 78, part 5, pp. 176-199, 1944.

[30] T. E. Starzl, "Peter Brian Medawar: father of transplantation," Journal of the American College of Surgeons, vol. 180, no. 3, pp. 332-336, 1995.

[31] G. D. Snell, "Methods for the study of histocompatibility genes," Journal of Genetics, vol. 49, no. 2, pp. 87-108, 1948.

[32] G. D. Snell and G. F. Higgins, "Alleles at the histocompatibility-2 locus in the mouse as determined by tumor transplantation," Genetics, vol. 36, no. 3, pp. 306-310, 1951.

[33] J. Klein, "George Snell's first foray into the unexplored territory of the major histocompatibility complex," Genetics, vol. 159, no. 2, pp. 435-439, 2001.

[34] J. Dausset, "Iso-leuko-antibodies," Acta Haematologica, vol. 20, no. 1-4, pp. 156-166, 1958.

[35] D. J. Charron, "In memoriam: Jean Dausset (1916-2009)," Tissue Antigens, vol. 74, no. 5, pp. 371-372, 2009.

[36] R. Payne, M. Tripp, J. Weigle, W. Bodmer, and J. Bodmer, "A new leukocyte isoantigen system in man," Cold Spring Harbor Symposia on Quantitative Biology, vol. 29, pp. 285-295, 1964.

[37] B. B. Levine, A. Ojeda, and B. Benacerraf, "Studies on artificial antigens. Iii. the genetic control of the immune response to hapten-poly-L-lysine conjugates in guinea pigs," The Journal of Experimental Medicine, vol. 118, pp. 953-957, 1963.
[38] B. Benacerraf and H. O. McDevitt, "Histocompatibilitylinked immune response genes," Science, vol. 175, no. 4019, pp. 273-279, 1972.

[39] L. Ellman, I. Green, W. J. Martin, and B. Benacerraf, "Linkage between the poly-L-lysine gene and the locus controlling the major histocompatibility antigens in strain 2 guinea pigs," Proceedings of the National Academy of Sciences of the United States of America, vol. 66, no. 2, pp. 322-328, 1970.

[40] H. O. McDevitt and M. L. Tyan, "Genetic control of the antibody response in inbred mice. Transfer of response by spleen cells and linkage to the major histocompatibility $(\mathrm{H}-$ 2) locus," The Journal of Experimental Medicine, vol. 128, no. 1, pp. 1-11, 1968.

[41] H. O. Mcdevitt and A. Chinitz, "Genetic control of the antibody response: relationship between immune response and histocompatibility (H-2) type," Science, vol. 163, no. 3872, pp. 1207-1208, 1969.

[42] R. M. Zinkernagel and P. C. Doherty, "Restriction of in vitro $\mathrm{T}$ cell mediated cytotoxicity in lymphocytic choriomeningitis within a syngeneic or semiallogeneic system," Nature, vol. 248, no. 5450, pp. 701-702, 1974.

[43] D. A. Brewerton, F. D. Hart, A. Nicholls, M. Caffrey, D. C. James, and R. D. Sturrock, "Ankylosing spondylitis and HLA 27,” The Lancet, vol. 1, no. 7809, pp. 904-907, 1973.

[44] L. Schlosstein, P. I. Terasaki, R. Bluestone, and C. M. Pearson, "High association of an HL-A antigen, W27, with ankylosing spondylitis," The New England Journal of Medicine, vol. 288, no. 14, pp. 704-706, 1973.

[45] J. Klein, F. Figueroa, and D. Klein, "H-2 haplotypes, genes, and antigens: second listing. I. Non-H-2 loci on chromosome 17," Immunogenetics, vol. 16, no. 4, pp. 285-317, 1982.

[46] F. Figueroa, S. Tewarson, E. Neufeld, and J. Klein, "H-2 haplotypes of strains DBR7, B10.NZW, NFS, BQ2, STU, TO1, and TO2," Immunogenetics, vol. 15, no. 4, pp. 431-436, 1982.

[47] S. Beck, D. Geraghty, H. Inoko, and L. Rowen, "Complete sequence and gene map of a human major histocompatibility complex," Nature, vol. 401, no. 6756, pp. 921-923, 1999.

[48] C. A. Stewart, R. Horton, R. J. N. Allock et al., "Complete MHC haplotype sequencing for common disease gene mapping," Genome Research, vol. 14, no. 6, pp. 1176-1187, 2004.

[49] R. Horton, L. Wilming, V. Rand et al., "Gene map of the extended human MHC," Nature Reviews Genetics, vol. 5, no. 12, pp. 889-899, 2004.

[50] R. Dressel, L. Walter, and E. Günther, "Genomic and functional aspects of the rat MHC, the RT1 complex," Immunological Reviews, vol. 184, pp. 82-95, 2001.

[51] D. M. Church, L. Goodstadt, L. W. Hillier et al., "Lineagespecific biology revealed by a finished genome assembly of the mouse," PLoS Biology, vol. 7, no. 5, Article ID e1000112, 2009.

[52] E. S. Lander, L. M. Linton, B. Birren et al., "Initial sequencing and analysis of the human genome," Nature, vol. 409, no. 6822, pp. 860-921, 2001.

[53] R. H. Waterston, K. Lindblad-Toh, E. Birney et al., "Initial sequencing and comparative analysis of the mouse genome," Nature, vol. 420, no. 6915, pp. 520-562, 2002.

[54] J. Trowsdale, "'Both man and bird and beast': comparative organization of MHC genes," Immunogenetics, vol. 41, no. 1, pp. 1-17, 1995.

[55] D. E. Geraghty, B. H. Koller, J. Pei, and J. A. Hansen, "Examination of four HLA class I pseudogenes: common events in the evolution of HLA genes and pseudogenes," Journal of Immunology, vol. 149, no. 6, pp. 1947-1956, 1992. 
[56] D. E. Geraghty, B. H. Koller, J. A. Hansen, and H. T. Orr, "The HLA class I gene family includes at least six genes and twelve pseudogenes and gene fragments," Journal of Immunology, vol. 149, no. 6, pp. 1934-1946, 1992.

[57] S. Beck and J. Trowsdale, "The human major histocompatibility complex: lessons from the DNA sequence," Annual Review of Genomics and Human Genetics, vol. 1, no. 2000, pp. 117-137, 2000.

[58] R. Ceppellini, E. S. Curtoni, R. L. Mattiuz et al., "Genetics of leukocyte antigens: a family study of segregation and linkage," Histocompatibility Testing, pp. 149-185, 1967.

[59] T. J. Xu, Y. N. Sun, and R. X. Wang, "Allelic polymorphism, gene duplication and balancing selection of the MHC class II DAB gene of Cynoglossus semilaevis (Cynoglossidae)," Genetics and Molecular Research, vol. 10, no. 1, pp. 53-64, 2011.

[60] P. C. Doherty and R. M. Zinkernagel, "Enhanced immunological surveillance in mice heterozygous at the $\mathrm{H}-2$ gene complex," Nature, vol. 256, no. 5512, pp. 50-52, 1975.

[61] B. Clarke and D. R. S. Kirby, "Maintenance of histocompatibility polymorphisms," Nature, vol. 211, no. 5052, pp. 999 1000, 1966.

[62] W. F. Bodmer, "Evolutionary significance of the HL-A system," Nature, vol. 237, no. 5351, pp. 139-183, 1972.

[63] N. Takahata and M. Nei, "Allelic genealogy under overdominant and frequency-dependent selection and polymorphism of major histocompatibility complex loci," Genetics, vol. 124, no. 4, pp. 967-978, 1990.

[64] R. W. Slade and H. I. McCallum, "Overdominant vs. frequency-dependent selection at MHC loci," Genetics, vol. 132, no. 3, pp. 861-862, 1992.

[65] R. J. De Boer, J. A. M. Borghans, M. Van Boven, C. Keşmir, and F. J. Weissing, "Heterozygote advantage fails to explain the high degree of polymorphism of the MHC," Immunogenetics, vol. 55, no. 11, pp. 725-731, 2004.

[66] V. Apanius, D. Penn, P. R. Slev, L. R. Ruff, and W. K. Potts, "The nature of selection on the major histocompatibility complex," Critical Reviews in Immunology, vol. 17, no. 2, pp. 179-224, 1997.

[67] R. M. Zinkernagel and P. C. Doherty, "Immunological surveillance against altered self components by sensitised $\mathrm{T}$ lymphocytes in lymphocytic choriomeningitis," Nature, vol. 251, no. 5475, pp. 547-548, 1974.

[68] K. M. Wegner, M. Kalbe, J. Kurtz, T. B. H. Reusch, and M. Milinski, "Parasite selection for immunogenetic optimality," Science, vol. 301, no. 5638, article 1343, 2003.

[69] S. Sommer, "The importance of immune gene variability (MHC) in evolutionary ecology and conservation," Frontiers in Zoology, vol. 2, article 16, 2005.

[70] J. L. Reinertsen, J. H. Klippel, and A. H. Johnson, "B-lymphocyte alloantigens associated with systemic lupus erythematosus," The New England Journal of Medicine, vol. 299, no. 10, pp. 515-518, 1978.

[71] A. Gibofsky, R. J. Winchester, and M. Patarroyo, "Disease associations of the Ia like human alloantigens. Contrasting patterns in rheumatoid arthritis and systemic lupus erythematosus," The Journal of Experimental Medicine, vol. 148, no. 6, pp. 1728-1732, 1978.

[72] O. Scherak, J. S. Smolen, and W. R. Mayr, "HLA-DRw3 and systemic lupus erythematosus," Arthritis and Rheumatism, vol. 23, no. 8, pp. 954-957, 1980.

[73] M. M. A. Fernando, C. R. Stevens, E. C. Walsh et al., "Defining the role of the MHC in autoimmunity: a review and pooled analysis," PLoS Genetics, vol. 4, no. 4, Article ID e1000024, 2008 .
[74] M. Michel, C. Johanet, O. Meyer et al., "Familial lupus erythematosus: clinical and immunologic features of 125 multiplex families," Medicine, vol. 80, no. 3, pp. 153-158, 2001.

[75] D. Kaplan, "The onset of disease in twins and siblings with systemic lupus erythematosus," Journal of Rheumatology, vol. 11, no. 5, pp. 648-652, 1984.

[76] F. C. Arnett, J. D. Reveille, and R. W. Wilson, "Systemic lupus erythematosus: current state of the genetic hypothesis," Seminars in Arthritis and Rheumatism, vol. 14, no. 1, pp. 2435, 1984.

[77] S. R. Block, J. B. Winfield, and M. D. Lockshin, "Studies of twins with systemic lupus erythematosus. A review of the literature and presentation of 12 additional sets," American Journal of Medicine, vol. 59, no. 4, pp. 533-552, 1975.

[78] D. Deapen, A. Escalante, L. Weinrib et al., "A revised estimate of twin concordance in systemic lupus erythematosus," Arthritis and Rheumatism, vol. 35, no. 3, pp. 311-318, 1992.

[79] I. Giles and D. Isenberg, "Lupus in the family-analysis of a cohort followed from 1978 to 1999," Lupus, vol. 10, no. 1, pp. 38-44, 2001.

[80] A. L. Sestak, B. G. Fürnrohr, J. B. Harley, J. T. Merrill, and B. Namjou, "The genetics of systemic lupus erythematosus and implications for targeted therapy," Annals of the Rheumatic Diseases, vol. 70, supplement 1, pp. i37-i43, 2011.

[81] T. J. Vyse and B. L. Kotzin, "Genetic susceptibility to systemic lupus erythematosus," Annual Review of Immunology, vol. 16, pp. 261-292, 1998.

[82] K. L. Moser, J. A. Kelly, C. J. Lessard, and J. B. Harley, "Recent insights into the genetic basis of systemic lupus erythematosus," Genes and Immunity, vol. 10, no. 5, pp. 373$379,2009$.

[83] V. Agnello, "Complement deficiency states," Medicine, vol. 57, no. 1, pp. 1-23, 1978.

[84] V. Agnello, "Association of systemic lupus erythematosus and SLE syndromes with hereditary and acquired complement deficiency states," Arthritis and Rheumatism, vol. 21, no. 5, supplement, pp. S146-S152, 1978.

[85] K. E. Sullivan, J. J. Wisnieski, J. A. Winkelstein et al., "Serum complement determinations in patients with quiescent systemic lupus erythematosus," Journal of Rheumatology, vol. 23, no. 12, pp. 2063-2067, 1996.

[86] J. S. Smolen, J. H. Klippel, and E. Penner, "HLA-DR antigens in systemic lupus erythematosus: association with specificity of autoantibody responses to nuclear antigens," Annals of the Rheumatic Diseases, vol. 46, no. 6, pp. 457-462, 1987.

[87] F. Tjernström, G. Hellmer, O. Nived, L. Truedsson, and G. Sturfelt, "Synergetic effect between interleukin-1 receptor antagonist allele (IL1RN $* 2)$ and MHC class II (DR17,DQ2) in determining susceptibility to systemic lupus erythematosus," Lupus, vol. 8, no. 2, pp. 103-108, 1999.

[88] G. E. Eroglu and P. F. Kohler, "Familial systemic lupus erythematosus: the role of genetic and environmental factors," Annals of the Rheumatic Diseases, vol. 61, no. 1, pp. 29-31, 2002.

[89] L. Morel, "Genetics of Human Lupus Nephritis," Seminars in Nephrology, vol. 27, no. 1, pp. 2-11, 2007.

[90] Y. Deng and B. P. Tsao, "Genetic susceptibility to systemic lupus erythematosus in the genomic era," Nature Reviews Rheumatology, vol. 6, no. 12, pp. 683-692, 2010.

[91] J.-W. Han, H.-F. Zheng, Y. Cui et al., "Genome-wide association study in a Chinese Han population identifies nine new susceptibility loci for systemic lupus erythematosus," Nature Genetics, vol. 41, no. 11, pp. 1234-1237, 2009. 
[92] J. B. Harley, M. E. Alarcón-Riquelme, L. A. Criswell et al., "Genome-wide association scan in women with systemic lupus erythematosus identifies susceptibility variants in ITGAM, PXK, KIAA1542 and other loci," Nature Genetics, vol. 40, no. 2, pp. 204-210, 2008.

[93] G. Hom, R. R. Graham, B. Modrek et al., "Association of systemic lupus erythematosus with C8orf13-BLK and ITGAMITGAX," The New England Journal of Medicine, vol. 358, no. 9, pp. 900-909, 2008.

[94] R. R. Graham, C. Cotsapas, L. Davies et al., "Genetic variants near TNFAIP3 on $6 \mathrm{q} 23$ are associated with systemic lupus erythematosus," Nature Genetics, vol. 40, no. 9, pp. 10591061, 2008.

[95] L. F. Barcellos, S. L. May, P. P. Ramsay et al., "High-density SNP screening of the major histocompatibility complex in systemic lupus erythematosus demonstrates strong evidence for independent susceptibility regions," PLoS Genetics, vol. 5, no. 10, Article ID e1000696, 2009.

[96] M. L. Budarf, P. Goyette, G. Boucher et al., "A targeted association study in systemic lupus erythematosus identifies multiple susceptibility alleles," Genes and Immunity, vol. 12, no. 1, pp. 51-58, 2011.

[97] N. Danchenko, J. A. Satia, and M. S. Anthony, "Epidemiology of systemic lupus erythematosus: a comparison of worldwide disease burden," Lupus, vol. 15, no. 5, pp. 308-318, 2006.

[98] E. A. Ruiz-Narvaez, P. A. Fraser, J. R. Palmer et al., "MHC region and risk of systemic lupus erythematosus in African American women," Human Genetics, vol. 130, no. 6, pp. 807815, 2011.

[99] P. S. Ramos, L. A. Criswell, K. L. Moser et al., "A comprehensive analysis of shared loci between systemic lupus erythematosus (SLE) and sixteen autoimmune diseases reveals limited genetic overlap," PLoS Genetics, vol. 7, no. 12, Article ID e1002406, 2011.

[100] S. T. Waters, S. M. Fu, F. Gaskin et al., "NZM2328: a new mouse model of systemic lupus erythematosus with unique genetic susceptibility loci," Clinical Immunology, vol. 100, no. 3, pp. 372-383, 2001.

[101] E. K. Wakeland, A. E. Wandstrat, K. Liu, and L. Morel, "Genetic dissection of systemic lupus erythematosus," Current Opinion in Immunology, vol. 11, no. 6, pp. 701-707, 1999.

[102] D. H. Kono and A. N. Theofilopoulos, "Genetics of SLE in mice," Springer Seminars in Immunopathology, vol. 28, no. 2, pp. 83-96, 2006.

[103] Z. Xu and L. Morel, "Genetics of systemic lupus erythematosus: contributions of mouse models in the era of human genome-wide association studies," Discovery Medicine, vol. 10, no. 50, pp. 71-78, 2010.

[104] L. Morel, D. Perry, A. Sang, Y. Yin, and Y. Y. Zheng, "Murine models of systemic lupus erythematosus," Journal of Biomedicine and Biotechnology, vol. 2011, Article ID 271694, 19 pages, 2011.

[105] A. Wandstrat and E. Wakeland, "The genetics of complex autoimmune diseases: non-MHC susceptibility genes," Nature Immunology, vol. 2, no. 9, pp. 802-809, 2001.

[106] M. Sengupta and L. Morel, "Lupus at the molecular level," Protein Cell, vol. 2, no. 12, pp. 941-943, 2011.

[107] L. Morel, C. Mohan, Y. Yu et al., "Functional dissection of systemic lupus erythematosus using congenic mouse strains," Journal of Immunology, vol. 158, no. 12, pp. 6019-6028, 1997.

[108] D. H. Kono, R. W. Burlingame, D. G. Owens et al., "Lupus susceptibility loci in New Zealand mice," Proceedings of the National Academy of Sciences of the United States of America, vol. 91, no. 21, pp. 10168-10172, 1994.
[109] C. Mohan, E. Alas, L. Morel, P. Yang, and E. K. Wakeland, "Genetic dissection of SLE pathogenesis. Sle1 on murine chromosome 1 leads to a selective loss of tolerance to H2A/ H2B/DNA subnuclesomes," The Journal of Clinical Investigation, vol. 101, no. 6, pp. 1362-1372, 1998.

[110] L. Morel, U. H. Rudofsky, J. A. Longmate, J. Schiffenbauer, and E. K. Wakeland, "Polygenic control of susceptibility to murine systemic lupus erythematosus," Immunity, vol. 1, no. 3, pp. 219-229, 1994.

[111] C. Mohan, L. Morel, P. Yang, and E. K. Wakeland, "Genetic dissection of systemic lupus erythematosus pathogenesis: Sle2 on murine chromosome 4 leads to B cell hyperactivity," Journal of Immunology, vol. 159, no. 1, pp. 454-465, 1997.

[112] U. H. Rudofsky, B. D. Evans, S. L. Balaban, V. D. Mottironi, and A. E. Gabrielsen, "Differences in expression of lupus nephritis in New Zealand Mixed H-2(z) homozygous inbred strains of mice derived from New Zealand Black and New Zealand White mice: origins and initial characterization," Laboratory Investigation, vol. 68, no. 4, pp. 419-426, 1993.

[113] L. Morel, K. R. Blenman, B. P. Croker, and E. K. Wakeland, "The major murine systemic lupus erythematosus susceptibility locus, Sle1, is a cluster of functionally related genes," Proceedings of the National Academy of Sciences of the United States of America, vol. 98, no. 4, pp. 1787-1792, 2001.

[114] Z. Xu, C. M. Cuda, B. P. Croker et al., "The NZM2410derived lupus susceptibility locus Sle2c1 increases Th17 polarization and induces nephritis in Fas-deficient mice," Arthritis and Rheumatism, vol. 63, no. 3, pp. 764-774, 2011.

[115] K. Liu, Q. Z. Li, Y. Yu et al., "Sle3 and Sle5 can independently couple with Sle1 to mediate severe lupus nephritis," Genes and Immunity, vol. 8, no. 8, pp. 634-645, 2007.

[116] C. M. Cuda, L. Zeumer, E. S. Sobel, B. P. Croker, and L. Morel, "Murine lupus susceptibility locus Sle1a requires the expression of two sub-loci to induce inflammatory T cells," Genes and Immunity, vol. 11, no. 7, pp. 542-553, 2010.

[117] Z. Xu, B. Duan, B. P. Croker, E. K. Wakeland, and L. Morel, "Genetic dissection of the murine lupus susceptibility locus Sle2: contributions to increased peritoneal B-1a cells and lupus nephritis map to different loci," Journal of Immunology, vol. 175, no. 2, pp. 936-943, 2005.

[118] J. Li, Y. Liu, C. Xie et al., "Deficiency of type I interferon contributes to Sle2-associated component lupus phenotypes," Arthritis and Rheumatism, vol. 52, no. 10, pp. 3063-3072, 2005.

[119] Y. Chen, C. Cuda, and L. Morel, "Genetic determination of T cell help in loss of tolerance to nuclear antigens," Journal of Immunology, vol. 174, no. 12, pp. 7692-7702, 2005.

[120] L. Morel, B. P. Croke, K. R. Blenman et al., "Genetic reconstitution of systemic lupus erythematosus immunopathology with polycongenic murine strains," Proceedings of the National Academy of Sciences of the United States of America, vol. 97, no. 12, pp. 6670-6675, 2000.

[121] S. Subramanian, Y. S. Yim, K. Liu, K. Tus, X. J. Zhou, and E. K. Wakeland, "Epistatic suppression of systemic lupus erythematosus: fine mapping of Sles1 to less than $1 \mathrm{Mb}$," Journal of Immunology, vol. 175, no. 2, pp. 1062-1072, 2005.

[122] L. Morel, X. H. Tian, B. P. Croker, and E. K. Wakeland, "Epistatic modifiers of autoimmunity in a murine model of lupus nephritis," Immunity, vol. 11, no. 2, pp. 131-139, 1999.

[123] T. J. Vyse, S. J. Rozzo, C. G. Drake et al., "Contributions of $\mathrm{Ea}(\mathrm{z})$ and $\mathrm{Eb}(\mathrm{z}) \mathrm{MHC}$ genes to lupus susceptibility in New Zealand mice," Journal of Immunology, vol. 160, no. 6, pp. 2757-2766, 1998. 
[124] T. N. Jørgensen, M. R. Gubbels, and B. L. Kotzin, "New insights into disease pathogenesis from mouse lupus genetics," Current Opinion in Immunology, vol. 16, no. 6, pp. 787793, 2004.

[125] E. Mozes, J. Lovchik, H. Zinger, and D. S. Singer, "MHC class I expression regulates susceptibility to spontaneous autoimmune disease in (NZBxNZW)F1 mice," Lupus, vol. 14, no. 4, pp. 308-314, 2005.

[126] S. Vidal, D. H. Kono, and A. N. Theofilopoulos, "Loci predisposing to autoimmunity in MRL-Fas(lpr) and C57BL/6Fas(lpr) mice," The Journal of Clinical Investigation, vol. 101, no. 3, pp. 696-702, 1998.

[127] P. Price, C. Witt, R. Allcock et al., "The genetic basis for the association of the 8.1 ancestral haplotype (A1, B8, DR3) with multiple immunopathological diseases," Immunological Reviews, vol. 167, pp. 257-274, 1999.

[128] M. J. Walport, C. M. Black, and J. R. Batchelor, "The immunogenetics of SLE," Clinics in Rheumatic Diseases, vol. 8, no. 1, pp. 3-21, 1982.

[129] D. Ulgiati and L. J. Abraham, "Comparative analysis of the disease-associated complement C4 gene from the HLA-A1, B8, DR3 haplotype," Experimental and Clinical Immunogenetics, vol. 13, no. 1, pp. 43-54, 1996.

[130] N. A. Bishof, T. R. Welch, L. S. Beischel, D. Carson, and P. A. Donnelly, "DP polymorphism in HLA-A1,-B8,-DR3 extended haplotypes associated with membranoproliferative glomerulonephritis and systemic lupus erythematosus," Pediatric Nephrology, vol. 7, no. 3, pp. 243-246, 1993.

[131] W. L. Griffing, S. B. Moore, and H. S. Luthra, "Associations of antibodies to native DNA with HLA-DRw3. A possible major histocompatibility complex-linked human immune response gene," The Journal of Experimental Medicine, vol. 152, no. 2, part 2, pp. 319s-325s, 1980.

[132] D. S. Singer, E. Mozes, S. Kirshner, and L. D. Kohn, "Role of MHC class I molecules in autoimmune disease," Critical Reviews in Immunology, vol. 17, no. 5-6, pp. 463-468, 1997.

[133] C. G. McPhee, T. J. Sproule, D.-M. Shin et al., "MHC class I family proteins retard systemic lupus erythematosus autoimmunity and B cell lymphomagenesis," Journal of Immunology, vol. 187, no. 9, pp. 4695-4704, 2011.

[134] O. T. M. Chan, V. Paliwal, J. M. McNiff, S. H. Park, A. Bendelac, and M. J. Shlomchik, "Deficiency in $\beta 2$ microglobulin, but not CD1, accelerates spontaneous lupus skin disease while inhibiting nephritis in MRL-Faslpr mice: an example of disease regulation at the organ level," Journal of Immunology, vol. 167, no. 5, pp. 2985-2990, 2001.

[135] E. Mozes, L. D. Kohn, F. Hakim, and D. S. Singer, "Resistance of MHC class I-deficient mice to experimental systemic lupus erythematosus," Science, vol. 261, no. 5117, pp. 91-93, 1993.

[136] G. J. Christianson, R. L. Blankenburg, T. M. Duffy et al., “ $\beta 2-$ Microglobulin dependence of the lupus-like autoimmune syndrome of MRL-lpr mice," Journal of Immunology, vol. 156, no. 12, pp. 4932-4939, 1996.

[137] C. M. Black, K. I. Welsh, and A. Fielder, "HLA antigens and Bf allotypes in SLE: evidence for the association being with specific haplotypes," Tissue Antigens, vol. 19, no. 2, pp. 115$120,1982$.

[138] A. Celada, C. Barras, G. Benzonana, and M. Jeannet, "Increased frequency of HLA-DRw3 in systemic lupus erythematosus," Tissue Antigens, vol. 15, no. 3, pp. 283-288, 1980.

[139] D. D. Gladman, P. I. Terasaki, M. S. Park et al., "Increased frequency of HLA-DRW2 in SLE," The Lancet, vol. 2, no. 8148, article $902,1979$.
[140] O. Scherak, J. S. Smolen, and W. R. Mayr, "Prevalence of HLA-DRw2 not increased in systemic lupus erythematosus," The New England Journal of Medicine, vol. 301, no. 11, p. 612, 1979.

[141] R. R. Graham, W. Ortmann, P. Rodine et al., "Specific combinations of HLA-DR2 and DR3 class II haplotypes contribute graded risk for disease susceptibility and autoantibodies in human SLE," European Journal of Human Genetics, vol. 15, no. 8, pp. 823-830, 2007.

[142] T. Paisansinsup, U. S. Deshmukh, V. R. Chowdhary, H. S. Luthra, S. M. Fu, and C. S. David, "HLA class II influences the immune response and antibody diversification to Ro60/Sjögren's syndrome-A: heightened antibody responses and epitope spreading in mice expressing HLA-DR molecules," Journal of Immunology, vol. 168, no. 11, pp. 58765884, 2002.

[143] C. Jiang, U. S. Deshmukh, F. Gaskin et al., "Differential responses to Smith D autoantigen by mice with HLA-DR and HLA-DQ transgenes: dominant responses by HLA-DR3 transgenic mice with diversification of autoantibodies to small nuclear ribonucleoprotein, double-stranded DNA, and nuclear antigens," Journal of Immunology, vol. 184, no. 2, pp. 1085-1091, 2010.

[144] D. S. Pisetsky, "Anti-DNA and autoantibodies," Current Opinion in Rheumatology, vol. 12, no. 5, pp. 364-368, 2000.

[145] F. Franceschini and I. Cavazzana, "Anti-Ro/SSA and La/SSB antibodies,” Autoimmunity, vol. 38, no. 1, pp. 55-63, 2005.

[146] J. Heward and S. C. L. Gough, "Genetic susceptibility to the development of autoimmune disease," Clinical Science, vol. 93, no. 6, pp. 479-491, 1997.

[147] R. G. Hamilton, J. B. Harley, W. B. Bias et al., "Two Ro (SS-A) autoantibody responses in systemic lupus erythematosus: correlation of HLA-DR/DQ specificities with quantitative expression of Ro (SS-A) autoantibody," Arthritis and Rheumatism, vol. 31, no. 4, pp. 496-505, 1988.

[148] T. J. Vyse, C. G. Drake, S. J. Rozzo, E. Roper, S. Izui, and B. L. Kotzin, "Genetic linkage of IgG autoantibody production in relation to lupus nephritis in New Zealand hybrid mice," The Journal of Clinical Investigation, vol. 98, no. 8, pp. 1762-1772, 1996.

[149] H. Yoshida, A. Kohno, and K. Ohta, "Genetic studies of autoimmunity in New Zealand mice. III. Associations among anti-DNA antibodies, NTA, and renal disease in (NZBxNZW)F1xNZW backcross Mice," Journal of Immunology, vol. 127, no. 2, pp. 433-437, 1981.

[150] M. R. Azizah, S. S. Ainol, S. H. Kuak, N. C. T. Kong, Y. Normaznah, and M. N. Rahim, "The association of the HLA class II antigens with clinical and autoantibody expression in Malaysian Chinese patients with systemic lupus erythematosus," Asian Pacific Journal of Allergy and Immunology, vol. 19, no. 2, pp. 93-100, 2001.

[151] K. Hartung, R. Coldewey, F. Krapf et al., "Hetero- and homozygosity of MHC class II gene products in systemic lupus erythematosus," Tissue Antigens, vol. 38, no. 4, pp. 165$168,1991$.

[152] P. Mattos and M. B. Santiago, "Association of antiphospholipid antibodies with valvulopathy in systemic lupus erythematosus: a systematic review," Clinical Rheumatology, vol. 30, no. 2, pp. 165-171, 2011.

[153] P. E. Love and S. A. Santoro, "Antiphospholipid antibodies: anticardiolipin and the lupus anticoagulant in systemic lupus erythematosus (SLE) and in non-SLE disorders. Prevalence and clinical significance," Annals of Internal Medicine, vol. 112, no. 9, pp. 682-698, 1990. 
[154] G. Ruiz-Irastorza, M. Crowther, W. Branch, and M. A. Khamashta, "Antiphospholipid syndrome," The Lancet, vol. 376, no. 9751, pp. 1498-1509, 2010.

[155] M. Savi, G. F. Ferraccioli, T. M. Neri et al., "HLA-DR antigens and anticardiolipin antibodies in Northern Italian systemic lupus erythematosus patients," Arthritis and Rheumatism, vol. 31, no. 12, pp. 1568-1570, 1988.

[156] M. R. Azizah, S. S. Ainol, N. C. Kong, Y. Normaznah, and M. N. Rahim, "HLA antigens in Malay patients with systemic lupus erythematosus: association with clinical and autoantibody expression," The Korean Journal of Internal Medicine, vol. 16, no. 2, pp. 123-131, 2001.

[157] L. Truedsson, G. Sturfelt, P. Johansen, O. Nived, and B. Thuresson, "Sharing of MHC haplotypes among patients with systemic lupus erythematosus from unrelated caucasian multicase families: disease association with the extended haplotype [HLA-B8,SCO1,DR17]," Journal of Rheumatology, vol. 22, no. 10, pp. 1852-1861, 1995.

[158] A. Jönsen, A. A. Bengtsson, G. Sturfelt, and L. Truedsson, "Analysis of HLA DR, HLA DQ, C4A, FcgammaRIIa, FcgammaRIIIa, MBL, and IL-1Ra allelic variants in Caucasian systemic lupus erythematosus patients suggests an effect of the combined FcgammaRIIa R/R and IL-1Ra 2/2 genotypes on disease susceptibility," Arthritis Research and Therapy, vol. 6, no. 6, pp. R557-R562, 2004.

[159] S. Skarsvag, K. E. Nansen, A. Hols, and T. Moen, "Distribution of HLA class II alleles among Scandinavian patients with systemic lupus erythematosus (SLE): an increased risk of SLE among non[DRB1*03,DQA1*0501,DQB1*0201] class II homozygotes?" Tissue Antigens, vol. 40, no. 3, pp. 128-133, 1992.

[160] Z. Yao, A. Kimura, K. Hartung et al., "Polymorphism of the DQA1 promoter region (QAP) and DRB1, QAP, DQA1, DQB1 haplotypes in systemic lupus erythematosus," Immunogenetics, vol. 38, no. 6, pp. 421-429, 1993.

[161] D. G. Doherty, R. Ireland, A. G. Demaine et al., "Major histocompatibility complex genes and susceptibility to systemic lupus erythematosus in Southern Chinese," Arthritis and Rheumatism, vol. 35, no. 6, pp. 641-646, 1992.

[162] Z. Yao, K. Hartung, H. G. Deicher et al., "Dna typing for HLA-DPB 1-alleles in German patients with systemic lupus erythematosus using the polymerase chain reaction and DIG-ddUTP-labelled oligonucleotide probes," European Journal of Immunogenetics, vol. 20, no. 4, pp. 259-266, 1993.

[163] F. Fouad, K. Johny, S. Kaaba, T. O. Alkarmi, P. Sharma, and S. Al-Harbi, "MHC in systemic lupus erythematosus: a study on a Kuwaiti population," European Journal of Immunogenetics, vol. 21, no. 1, pp. 11-14, 1994.

[164] R. R. Graham, W. A. Ortmann, C. D. Langefeld et al., "Visualizing human leukocyte antigen class II risk haplotypes in human systemic lupus erythematosus," American Journal of Human Genetics, vol. 71, no. 3, pp. 543-553, 2002.

[165] M. M. Fernando, C. R. Stevens, P. C. Sabeti et al., "Identification of two independent risk factors for lupus within the MHC in United Kingdom families," PLoS Genetics, vol. 3, no. 11, article e192, 2007.

[166] K. Hartung, M. P. Baur, R. Coldewey et al., "Major histocompatibility complex haplotypes and complement C4 alleles in systemic lupus erythematosus. Results of a multicenter study," The Journal of Clinical Investigation, vol. 90, no. 4, pp. 1346-1351, 1992.

[167] P. F. Halloran, J. Urmson, V. Ramassar, C. Laskin, and P. Autenried, "Increased class I and class II MHC products and
mRNA in kidneys of MRL-1pr/1pr mice3 during autoimmune nephritis and inhibition by cyclosporine," Journal of Immunology, vol. 141, no. 7, pp. 2303-2312, 1988.

[168] A. M. Jevnikar, M. J. Grusby, and L. H. Glimcher, "Prevention of nephritis in major histocompatibility complex class IIdeficient MRL-lpr mice," The Journal of Experimental Medicine, vol. 179, no. 4, pp. 1137-1143, 1994.

[169] A. N. Theofilopoulos and F. J. Dixon, "Etiopathogenesis of murine SLE," Immunological Reviews, vol. 55, pp. 179-216, 1981.

[170] H. Sekine, K. L. Graham, S. Zhao et al., "Role of MHC-linked genes in autoantigen selection and renal disease in a murine model of systemic lupus erythematosus," Journal of Immunology, vol. 177, no. 10, pp. 7423-7434, 2006.

[171] J. B. Howie and B. J. Helyer, "The immunology and pathology of NZB mice," Advances in Immunology, vol. 9, pp. 215-266, 1968.

[172] S. Hirose, R. Nagasawa, and I. Sekikawa, "Enhancing effect of $\mathrm{H}$-2-linked NZW gene(s) on the autoimmune traits of (NZB x NZW)F1 mice," The Journal of Experimental Medicine, vol. 158, no. 1, pp. 228-233, 1983.

[173] S. Hirose, G. Ueda, and K. Noguchi, "Requirement of H-2 heterozygosity for autoimmunity in (NZB x NZW)F1 hybrid mice," European Journal of Immunology, vol. 16, no. 12, pp. 1631-1633, 1986.

[174] D. Zhang, K. Fujio, Y. Jiang et al., "Dissection of the role of MHC class II A and E genes in autoimmune susceptibility in murine lupus models with intragenic recombination," Proceedings of the National Academy of Sciences of the United States of America, vol. 101, no. 38, pp. 13838-13843, 2004.

[175] S. Hirose, K. Kinoshita, S. Nozawa, H. Nishimura, and Shirai, "Effects of major histocompatibility complex on autoimmune disease of H-2-congenic New Zealand mice," International Immunology, vol. 2, no. 11, pp. 1091-1095, 1990.

[176] E. D. Murphy and J. B. Roths, "A Y chromosome associated factor in strain BXSB producing accelerated autoimmunity and lymphoproliferation," Arthritis and Rheumatism, vol. 22, no. 11, pp. 1188-1194, 1979.

[177] J. A. Deane, P. Pisitkun, R. S. Barrett et al., "Control of toll-like receptor 7 expression is essential to restrict autoimmunity and dendritic cell proliferation," Immunity, vol. 27, no. 5, pp. 801-810, 2007.

[178] D. H. Kono, M. K. Haraldsson, B. R. Lawson et al., "Endosomal TLR signaling is required for anti-nucleic acid and rheumatoid factor autoantibodies in lupus," Proceedings of the National Academy of Sciences of the United States of America, vol. 106, no. 29, pp. 12061-12066, 2009.

[179] J. Kelley, M. R. Johnson, G. S. Alarcón, R. P. Kimberly, and J. C. Edberg, "Variation in the relative copy number of the TLR7 gene in patients with systemic lupus erythematosus and healthy control subjects," Arthritis and Rheumatism, vol. 56, no. 10, pp. 3375-3378, 2007.

[180] N. Shen, Q. Fu, Y. Deng et al., "Sex-specific association of X-linked toll-like receptor 7 (TLR7) with male systemic lupus erythematosus," Proceedings of the National Academy of Sciences of the United States of America, vol. 107, no. 36, pp. 15838-15843, 2010.

[181] A. Kawasaki, H. Furukawa, Y. Kondo et al., "TLR7 singlenucleotide polymorphisms in the 3' untranslated region and intron 2 independently contribute to systemic lupus erythematosus in Japanese women: a case-control association study," Arthritis Research and Therapy, vol. 13, no. 2, article R41, 2011. 
[182] H. García-Ortiz, R. Velázquez-Cruz, F. Espinosa-Rosales, S. Jiménez-Morales, V. Baca, and L. Orozco, "Association of TLR7 copy number variation with susceptibility to childhood-onset systemic lupus erythematosus in Mexican population," Annals of the Rheumatic Diseases, vol. 69, no. 10, pp. 1861-1865, 2010.

[183] P. F. Zipfel, "Complement and immune defense: from innate immunity to human diseases," Immunology Letters, vol. 126, no. 1-2, pp. 1-7, 2009.

[184] P. F. Zipfel and C. Skerka, "Complement regulators and inhibitory proteins," Nature Reviews Immunology, vol. 9, no. 10, pp. 729-740, 2009.

[185] M. G. Tansey and D. E. Szymkowski, "The TNF superfamily in 2009: new pathways, new indications, and new drugs," Drug Discovery Today, vol. 14, no. 23-24, pp. 1082-1088, 2009.

[186] I. S. Grewal, "Overview of TNF superfamily: a chest full of potential therapeutic targets," Advances in Experimental Medicine and Biology, vol. 647, pp. 1-7, 2009.

[187] M. Daugaard, M. Rohde, and M. Jäättelä, "The heat shock protein 70 family: highly homologous proteins with overlapping and distinct functions," FEBS Letters, vol. 581, no. 19, pp. 3702-3710, 2007.

[188] G. Kudla, A. Helwak, and L. Lipinski, "Gene conversion and GC-content evolution in mammalian Hsp70," Molecular Biology and Evolution, vol. 21, no. 7, pp. 1438-1444, 2004.

[189] J. V. Sarma and P. A. Ward, "The complement system," Cell and Tissue Research, vol. 343, no. 1, pp. 227-235, 2011.

[190] M. V. Carroll and R. B. Sim, "Complement in health and disease," Advanced Drug Delivery Reviews, vol. 63, no. 12, pp. 965-975, 2011.

[191] J. S. Navratil, L. C. Korb, and J. M. Ahearn, "Systemic lupus erythematosus and complement deficiency: clues to a novel role for the classical complement pathway in the maintenance of immune tolerance," Immunopharmacology, vol. 42, no. 13, pp. 47-52, 1999.

[192] H. T. Cook and M. Botto, "Mechanisms of disease: the complement system and the pathogenesis of systemic lupus erythematosus," Nature Clinical Practice Rheumatology, vol. 2, no. 6, pp. 330-337, 2006.

[193] M. C. Pickering, M. Botto, P. R. Taylor, P. J. Lachmann, and M. J. Walport, "Systemic lupus erythematosus, complement deficiency, and apoptosis," Advances in Immunology, vol. 76, pp. 227-324, 2000.

[194] B. P. Morgan and M. J. Walport, "Complement deficiency and disease," Immunology Today, vol. 12, no. 9, pp. 301-306, 1991.

[195] H. R. Colten, "Molecular genetics of the major histocompatibility linked complement genes," Springer Seminars in Immunopathology, vol. 6, no. 2-3, pp. 149-158, 1983.

[196] K. Kölble and K. B. Reid, "Genetic deficiencies of the complement system and association with disease-early components," International Reviews of Immunology, vol. 10, no. 1, pp. 17-36, 1993.

[197] D. Glass, D. Raum, and D. Gibson, "Inherited deficiency of the second component of complement. Rheumatic disease associations," The Journal of Clinical Investigation, vol. 58, no. 4, pp. 853-861, 1976.

[198] A. H. L. Fielder, M. J. Walport, and J. R. Batchelor, "Family study of the major histocompatibility complex in patients with systemic lupus erythematosus: importance of null alleles of C4A and C4B in determining disease susceptibility," BMJ, vol. 286, no. 6363, pp. 425-428, 1983.

[199] C. Y. Yu, K. T. Belt, C. M. Giles, R. D. Campbell, and R. R. Porter, "Structural basis of the polymorphism of human complement components C4A and C4B: gene size, reactivity and antigenicity," The EMBO Journal, vol. 5, no. 11, pp. 28732881, 1986.

[200] G. Mauff, B. Luther, P. M. Schneider et al., "Reference typing report for complement component C4," Experimental and Clinical Immunogenetics, vol. 15, no. 4, pp. 249-260, 1998.

[201] Y. Yang, E. K. Chung, L. W. Yee et al., "Gene copy-number variation and associated polymorphisms of complement component $\mathrm{C} 4$ in human systemic lupus erythematosus (SLE): low copy number is a risk factor for and high copy number is a protective factor against SLE susceptibility in European Americans," American Journal of Human Genetics, vol. 80, no. 6, pp. 1037-1054, 2007.

[202] M. L. Olsen, R. Goldstein, F. C. Arnett, M. Duvic, M. Pollack, and J. D. Reveille, "C4A gene deletion and HLA associations in black Americans with systemic lupus erythematosus," Immunogenetics, vol. 30, no. 1, pp. 27-33, 1989.

[203] M. Botto, K. Y. Fong, A. K. So et al., "Homozygous hereditary C3 deficiency due to a partial gene deletion," Proceedings of the National Academy of Sciences of the United States of America, vol. 89, no. 11, pp. 4957-4961, 1992.

[204] K. A. Davies, J. A. Schifferli, and M. J. Walport, "Complement deficiency and immune complex disease," Springer Seminars in Immunopathology, vol. 15, no. 4, pp. 397-416, 1994.

[205] L. E. M ũoz, K. Lauber, M. Schiller, A. A. Manfredi, and M. Herrmann, "The role of defective clearance of apoptotic cells in systemic autoimmunity," Nature Reviews Rheumatology, vol. 6 , no. 5, pp. 280-289, 2010.

[206] M. C. Carroll, "The role of complement in B cell activation and tolerance," Advances in Immunology, no. 74, pp. 61-88, 2000.

[207] P. E. Lipsky, "Systemic lupus erythematosus: an autoimmune disease of B cell hyperactivity," Nature Immunology, vol. 2, no. 9, pp. 764-766, 2001.

[208] S. N. Pattanakitsakul, J. H. Zheng, S. Natsuume-Sakai, M. Takahashi, and M. Nonaka, "Aberrant splicing caused by the insertion of the B2 sequence into an intron of the complement $\mathrm{C} 4$ gene is the basis for low $\mathrm{C} 4$ production in $\mathrm{H}$ 2(k) mice," The Journal of Biological Chemistry, vol. 267, no. 11, pp. 7814-7820, 1992.

[209] M. J. Garlepp, D. A. Hart, and M. J. Fritzler, "Regulation of plasma complement C4 and Factor B levels in murine systemic lupus erythematosus," Journal of Clinical and Laboratory Immunology, vol. 28, no. 3, pp. 137-141, 1989.

[210] M. Botto, C. Dell’Agnola, A. E. Bygrave et al., "Homozygous C1q deficiency causes glomerulonephritis associated with multiple apoptotic bodies," Nature Genetics, vol. 19, no. 1, pp. 56-59, 1998.

[211] M. Botto, "Links between complement deficiency and apoptosis," Arthritis Research, vol. 3, no. 4, pp. 207-210, 2001.

[212] P. R. Taylor, A. Carugati, V. A. Fadok et al., "A hierarchical role for classical pathway complement proteins in the clearance of apoptotic cells in vivo," The Journal of Experimental Medicine, vol. 192, no. 3, pp. 359-366, 2000.

[213] F. Ritossa, "Discovery of the heat shock response," Cell Stress and Chaperones, vol. 1, no. 2, pp. 97-98, 1996.

[214] B. J. M. Ripley, D. A. Isenberg, and D. S. Latchman, "Elevated levels of the $90 \mathrm{kDa}$ heat shock protein (hsp90) in SLE correlate with levels of IL-6 and autoantibodies to hsp90," Journal of Autoimmunity, vol. 17, no. 4, pp. 341-346, 2001.

[215] L. Walter, F. Rauh, and E. Gunther, "Comparative analysis of the three major histocompatibility complex-linked heat shock protein 70 (Hsp70) genes of the rat," Immunogenetics, vol. 40, no. 5, pp. 325-330, 1994. 
[216] F. Favatier, L. Bornman, L. E. Hightower, E. Günther, and B. S. Polla, "Variation in hsp gene expression and Hsp polymorphism: do they contribute to differential disease susceptibility and stress tolerance?" Cell Stress and Chaperones, vol. 2, no. 3, pp. 141-155, 1997.

[217] W. Jarjour, A. M. Reed, J. Gauthier, S. Hunt, and J. B. Winfield, "The 8.5-kb PstI allele of the stress protein gene, Hsp70-2: an independent risk factor for systemic lupus erythematosus in African Americans?" Human Immunology, vol. 45, no. 1, pp. 59-63, 1996.

[218] T. Hehlgans and K. Pfeffer, "The intriguing biology of the tumour necrosis factor/tumour necrosis factor receptor superfamily: players, rules and the games," Immunology, vol. 115, no. 1, pp. 1-20, 2005.

[219] W. P. Cawthorn and J. K. Sethi, "TNF- $\alpha$ and adipocyte biology," FEBS Letters, vol. 582, no. 1, pp. 117-131, 2008.

[220] B. J. Sugarman, B. B. Aggarwal, and P. E. Hass, "Recombinant human tumor necrosis factor- $\alpha$ : effects on proliferation of normal and transformed cells in vitro," Science, vol. 230, no. 4728, pp. 943-945, 1985.

[221] B. Beutler and A. Cerami, "The biology of cachectin/TNFa primary mediator of the host response," Annual Review of Immunology, vol. 7, pp. 625-655, 1989.

[222] M. Zembala, D. Kowalczyk, J. Pryjma et al., "The role of tumor necrosis factor in the regulation of antigen presentation by human monocytes," International Immunology, vol. 2, no. 4, pp. 337-342, 1990.

[223] A. G. Wilson, F. S. Di Giovine, A. I. F. Blakemore, and G. W. Duff, "Single base polymorphism in the human Tumour Necrosis Factor alpha (TNF $\alpha)$ gene detectable by NcoI restriction of PCR product," Human Molecular Genetics, vol. 1 , no. 5, article 353, 1992.

[224] A. G. Wilson, C. Gordon, F. S. Di Giovine et al., "A genetic association between systemic lupus erythematosus and tumor necrosis factor alpha," European Journal of Immunology, vol. 24, no. 1, pp. 191-195, 1994.

[225] M. Rudwaleit, M. Tikly, M. Khamashta et al., "Interethnic differences in the association of tumor necrosis factor promoter polymorphisms with systemic lupud erythematosus," Journal of Rheumatology, vol. 23, no. 10, pp. 1725-1728, 1996.

[226] M. J. Rood, M. V. Van Krugten, E. Zanelli et al., "TNF308A and HLA-DR3 alleles contribute independently to susceptibility to systemic lupus erythematosus," Arthritis and Rheumatism, vol. 43, no. 1, pp. 129-134, 2000.

[227] H. Schotte, P. Willeke, N. Tidow et al., "Extended haplotype analysis reveals an association of TNF polymorphisms with susceptibility to systemic lupus erythematosus beyond HLADR3," Scandinavian Journal of Rheumatology, vol. 34, no. 2, pp. 114-121, 2005.

[228] U. Muller, C. V. Jongeneel, and S. A. Nedospasov, "Tumour necrosis factor and lymphotoxin genes map close to $\mathrm{H}-2 \mathrm{D}$ in the mouse major histocompatibility complex," Nature, vol. 325, no. 6101, pp. 265-267, 1987.

[229] C. O. Jacob, F. Hwang, G. D. Lewis, and A. M. Stall, "Tumor necrosis factor alpha in murine systemic lupus erythematosus disease models: implications for genetic predisposition and immune regulation," Cytokine, vol. 3, no. 6, pp. 551-561, 1991.

[230] C. O. Jacob and H. O. McDevitt, "Tumour necrosis factor- $\alpha$ in murine autoimmune "lupus" nephritis," Nature, vol. 331, no. 6154, pp. 356-358, 1988.

[231] D. Kontoyiannis and G. Kollias, "Accelerated autoimmunity and lupus nephritis in NZB mice with an engineered heterozygous deficiency in tumor necrosis factor," European Journal of Immunology, vol. 30, no. 7, pp. 2038-2047, 2000.
[232] K. Artzt, D. Barlow, W. F. Dove et al., "Mouse chromosome 17," Mammalian Genome, vol. 1, no. 1, pp. S280-S300, 1991.

[233] T. Endo, T. Imanishi, T. Gojobori, and H. Inoko, "Evolutionary significance of intra-genome duplications on human chromosomes," Gene, vol. 205, no. 1-2, pp. 19-27, 1997. 


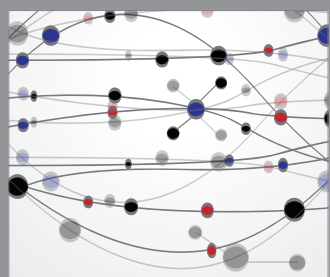

The Scientific World Journal
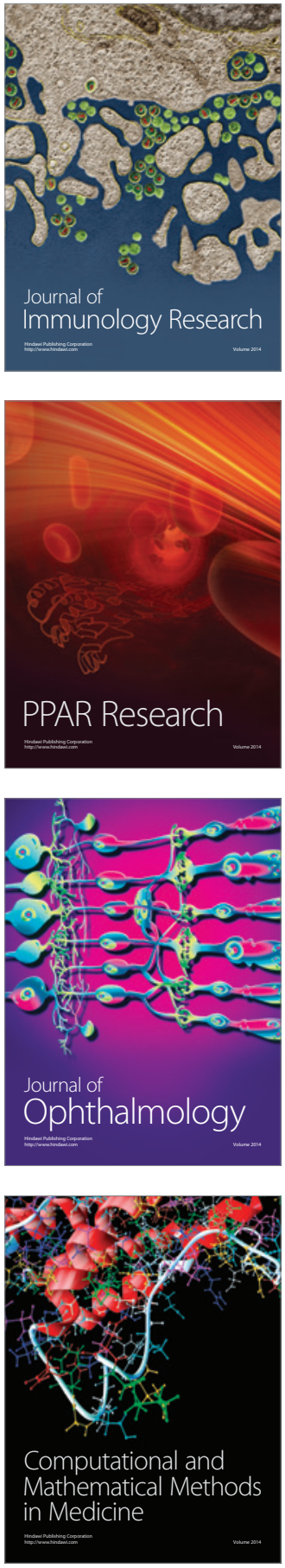

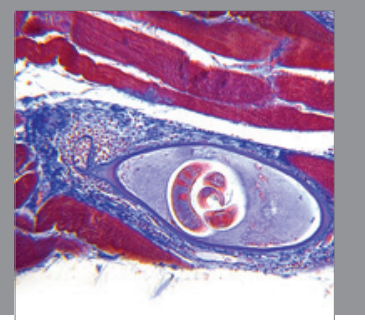

Gastroenterology

Research and Practice
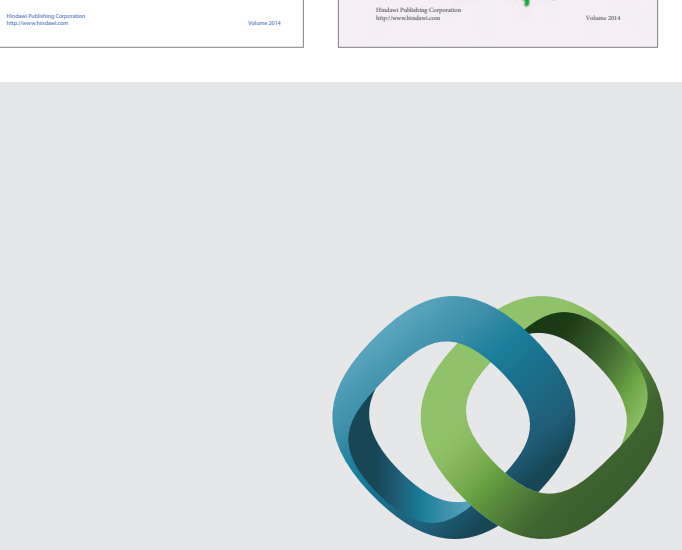

\section{Hindawi}

Submit your manuscripts at

http://www.hindawi.com
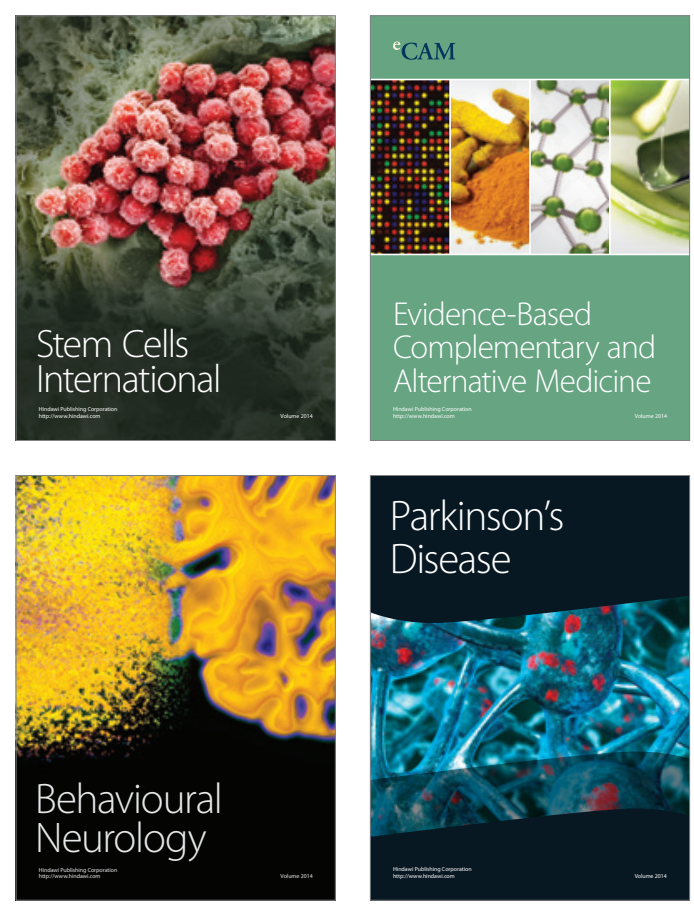

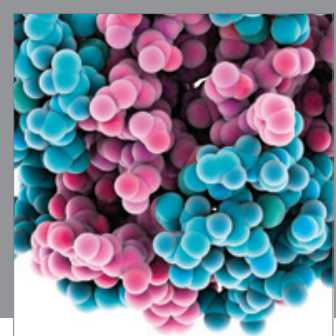

Journal of
Diabetes Research

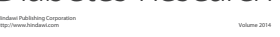

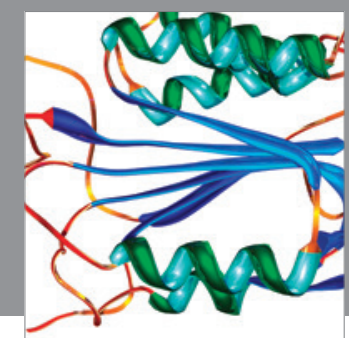

Disease Markers
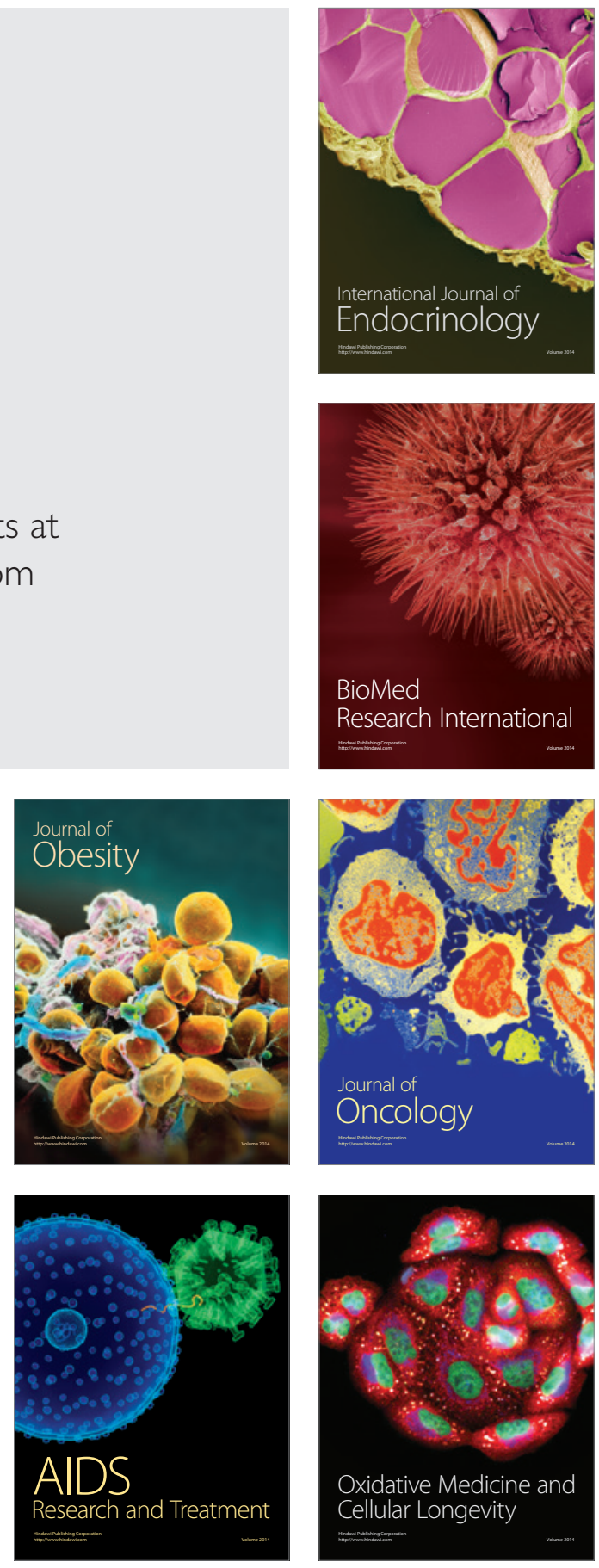